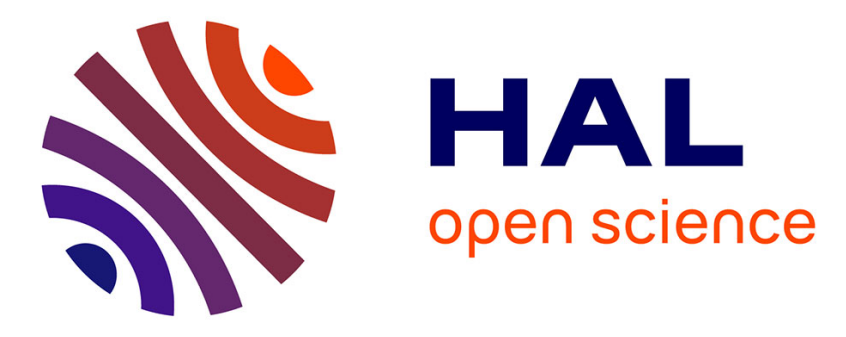

\title{
Damage assessment of ancient masonry churches stroked by the Central Italy earthquakes of 2016 by the non-smooth contact dynamics method
}

\author{
Francesco Clementi, Angela Ferrante, Ersilia Giordano, Frédéric Dubois, \\ Stefano Lenci
}

\section{To cite this version:}

Francesco Clementi, Angela Ferrante, Ersilia Giordano, Frédéric Dubois, Stefano Lenci. Damage assessment of ancient masonry churches stroked by the Central Italy earthquakes of 2016 by the non-smooth contact dynamics method. Bulletin of Earthquake Engineering, 2019, 10.1007/s10518019-00613-4 . hal-02127095

\section{HAL Id: hal-02127095 \\ https://hal.science/hal-02127095}

Submitted on 13 May 2019

HAL is a multi-disciplinary open access archive for the deposit and dissemination of scientific research documents, whether they are published or not. The documents may come from teaching and research institutions in France or abroad, or from public or private research centers.
L'archive ouverte pluridisciplinaire HAL, est destinée au dépôt et à la diffusion de documents scientifiques de niveau recherche, publiés ou non, émanant des établissements d'enseignement et de recherche français ou étrangers, des laboratoires publics ou privés. 


\title{
Damage assessment of ancient masonry churches stroked by the Central Italy earthquakes of 2016 by the non-smooth contact dynamics method
}

\author{
Francesco Clementi ${ }^{1}$ (D) Angela Ferrante ${ }^{1}$ - Ersilia Giordano ${ }^{1} \cdot$ Frédéric Dubois $^{2}$. \\ Stefano Lenci ${ }^{1}$
}

\begin{abstract}
The non-smooth contact dynamics method was selected to investigate the damage occurred to typical masonry churches (namely Apennine churches) belonging to Central Italy areas affected by the seismic activity started in 2016. The investigated buildings show discontin-uous dynamics since the optioned method gave the chance to properly model the temples as multi rigid body systems using the Signorini's impenetrability condition and the dry-friction Coulomb's law, achieving a thoughtful response to ground seismic solicitations. The results provided by the assessment grant an overview of the most common damages and failure mechanisms, giving the guidelines to restoration projects that fully respond to structural needs.
\end{abstract}

Keywords Non-smooth contact dynamics $\cdot$ Central Italy earthquake $\cdot$ Historical structures $\cdot$ Apennine churches $\cdot$ Damage survey

\section{Introduction}

The intense seismic activity that affected numerous territories of Italy during most recent decades indicates how much cultural heritage and its protection should be taken into proper account. Evaluating the seismic weakness of such a significant legacy might be challeng-ing, considering how unique these structures are, requiring modern and computationally substantial numerical models to have a legitimate estimation of their dynamical reaction under seismic activity. The latest Italian tremors (Umbria-Marche 1997-1998, Abruzzo 2009, Emilia-Romagna 2012, Central Italy 2016), endangered a huge part of the build-ing heritage, such as strategic buildings, churches and steeples (Lagomarsino and Podestà 2004; Krstevska et al. 2010; Milani 2013; Brandonisio et al. 2013; Clementi et al. 2017b).

Francesco Clementi

francesco.clementi@univpm.it

1 Department of Civil and Building Engineering, and Architecture, Polytechnic University of Marche, via Brecce Bianche, 60131 Ancona, Italy

2 Laboratoire de Mécanique et Génie Civil, CNRS, University Montpellier, Montpellier, France 
The relevance of assessing the vulnerability of cultural heritage against earthquakes has become an essential pre-requisite for constant safety of city centers, considering the massive presence of peculiar existing structures in the European area (Roca et al. 2013; Formisano et al. 2017; Betti et al. 2018; Valente and Milani 2018). Churches are expressly widespread in Italy, particularly in high-seismicity regions, and they are characterized by complex geometries, irregularities, and highly heterogeneous materials, all features that make them much vulnerable during a seismic event. The damages are often caused by the failure of the box behavior due to the absence of the connections between different structural parts, walls, and floors, thrusting arches and tin vaults. The collapse may be caused by a concentration of stress.

Thus, the ancient masonry structures may be seen as discontinuous structural systems composed of units (e.g., bricks, stones, blocks, etc.), bonded together with or without mortar. Moreover, for a numerical model to adequately represent the behavior of a real structure, both input materials' properties and constitutive laws should be selected carefully by the modeler, considering the alteration of masonry characteristics and the different range of stresses within masonry structures (Terracciano et al. 2015; Clementi et al. 2015; Pantò et al. 2016; Sarhosis et al. 2018; Formisano et al. 2018).

It has been shown that right before or during a collapse the blocks slide and impact between them, in a typical non-smooth dynamic behavior. The study of this behavior for historical structures is critical to identify the typology of collapse. The study of masonry buildings usually options the Finite Element Method (Pierdicca et al. 2016; Formisano 2016; Formisano and Marzo 2017; Quagliarini et al. 2017); this approach is usually employed to analyze the response and the damage beyond the elastic behavior using appropriate constitutive laws (Milani and Valente 2015; Clementi et al. 2016, 2017a, 2018; Acito et al. 2016; Milani et al. 2017), but it cannot be able to reproduce the interaction between the blocks. Even sophisticated analyses such as micro-modeling that distinguishes blocks, mortar and interface cannot reproduce the non-smooth behaviour near the collapse. This paper uses the advance rigid-body dynamics formulation for such reasons.

While the selected model adopts stiff blocks, based on the consistent description of associative friction laws at the contact surfaces. The consistency and benefits of this approach are based on how it characterises masonry heritage, which is susceptible to uncertainty collapse because of the high incidence of the compressive strength over tensile one. Moreover, modelling very rigid blocks provides the opportunity to reproduce the stick-slip transition, representing a sudden change in motion at the collision. This is a typical contact phenomenon that strongly affects the failure mechanism and the corresponding ultimate load. Furthermore, the fact that the joints form predefined natural planes of weakness makes this analysis, namely the distinct element method (DEM), particularly striking.

Several studies are currently available in literature dealing with the numerical/ experi-mental analysis of masonry churches. To the best of the authors' knowledge, the non-smooth nature of the dynamic response of churches is not analyzed in depth (Lancioni et al. 2013). For this reason, in the present work the dynamics of five different typical masonry churches, damaged during the last Central Italy seismic sequence, are inves-tigated numerically by means of a DEM code which implements the non-smooth con-tact dynamics (NSCD) method (Moreau 1988; Chetouane et al. 2005). Thus, it is pos-sible to have an objective validation on the legitimacy of the method in the conditions of incipient collapse, and on its drawbacks if necessary, as one of the main goals of this paper. The masonry is idealized using an assembly of stiff bodies approximately equal to the real geometry of bricks, but with greater dimensions to take into account the thickness of the mortar. The analyses are done with the solver LMGC90() which is 
interfaced with a pre-processor, made directly by the authors and able to design complex 3D masonry structures, leading to a better discretization of the real geometries (one of the major drawbacks of the method) decreasing the amount of time required to create them. In fact, respect to previous works (Lancioni et al. 2013, 2016), a bigger number of solid are implemented with a huge decrease of time to create them, finally increasing the accuracy of the performed calculation. A post-processing program, allowing to plot all the quantities of interest, is used in order to compare the numerical predictions with the real damages. Similarly, it was possible to analyze the interaction of the solver with a third-part program, to extend its use even to early practitioners.

The churches considered in this study are the San Francesco church in Montefortino, in the province of Fermo, the San Francesco church in Sarnano, the Sant'Anna church in Camerino, the Sant'Antonio church in Ussita, the Madonna of Valcora Sanctuary in Fiuminata, all in the province of Macerata, Central Italy, Fig. 1.

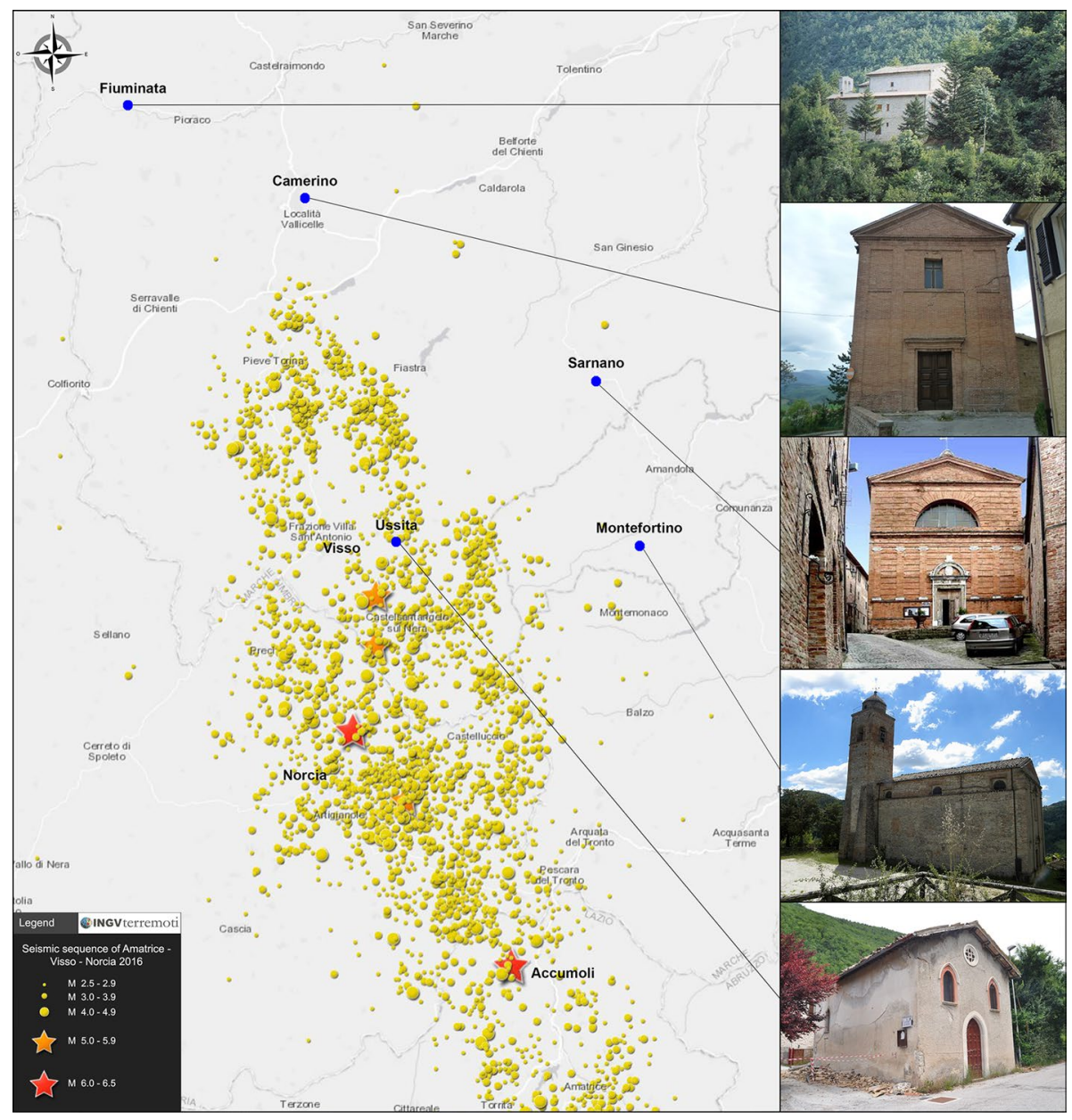

Fig. 1 Location of the churches analyzed in Central Italy 


\section{Structural characteristics of the analysed churches}

The investigated churches in the area struck by the Central Italy earthquakes between the end of 2016 and the first months of 2017 are marked by a particular structural kind, which is very different from the ones damaged by the seismic shocks of L'Aquila in 2009 and Emilia Romagna in 2012. In the Apennine zones, at least in the Marche region zones, there are mainly numerous, sparse and few populated villages on hilltops or small valleys, characterizing the urban areas (e.g., Visso, Ussita, Castelsantangelo sul Nera, Fiastra, Arquata del Tronto, etc.). For example, the Municipality of Ussita, one of the most severely damaged centers in the Marche Region, is divided into 12 hamlets, with a total population of 444 inhabitants. Most of these tiny villages typically have a small local church situated right at the center of the main village or in the center of the hamlet.

The structural development of these churches takes into account the historical seismicity of the area, thus often leading to the realization of small single-nave churches, without apses, with recurrent windows located on the two long sides of the church. Typically, the façade of the main entrance has a rose window, with a distinctive parapet with triangular or rectangular geometry, whose tallness surpasses the edge of the rooftop. The side walls of this type of churches are usually made of stone masonry and often support wooden trusses. As a rule, in several cases, a little belfry or a bell-gable is additionally present on the side of the structure. Moreover, these churches are usually much smaller than the traditional Italian ones. They were based on simple architectonic modules and were often built with local materials, old brick masonries and mortar with very poor mechanical properties.

Frequently, this type of structures is not characterized by a box-like behavior, due to the absence of a robust connection between their structural components. Consequently, the seismic response of churches is mostly governed by the activation of local mechanisms of macro-elements (Lagomarsino and Podestà 2004; Giresini 2016; Giresini and Sassu 2017). One of the principal consequences of this response is the relevant vulnerability of churches, even higher than usual masonry building stocks (Giordano et al. 2019).

The remaining part of the stock of churches are located in the main cities at the base of the Apennines (i.e., Camerino, Norcia, Ascoli Piceno, etc.), showing a more complex geometry than the previous ones, and they will be taken into account in future works.

The following paragraphs contain a concise description of the main historical and geometrical features of the analyzed "Apennine churches".

\subsection{San Francesco church in Montefortino (Central Italy, Marche Region, Fermo province)}

The San Francesco Church was built in the fifteenth century on the remains of the ancient Santa Maria of Girone church. The church has a Romanesque-Gothic style, featured with a unique nave with a length of $10.89 \mathrm{~m}$, and a width of $20.36 \mathrm{~m}$, and a maximum height of $15.53 \mathrm{~m}$. The apse has dimensions $9.36 \mathrm{~m}$ of length and $7.1 \mathrm{~m}$ of width and covered by a barrel vault. The belfry is on the north façade with a height of $24.24 \mathrm{~m}$ (see Fig. 2). Following the earthquake occurred in September 1997, the church suffered serious damages on the façade, on the vault of the apse and the upper part of the tower and some retrofitting interventions were carried out in the following years. The roof is made with timber elements. The bearing structure is made of disordered rubble stone masonry. 

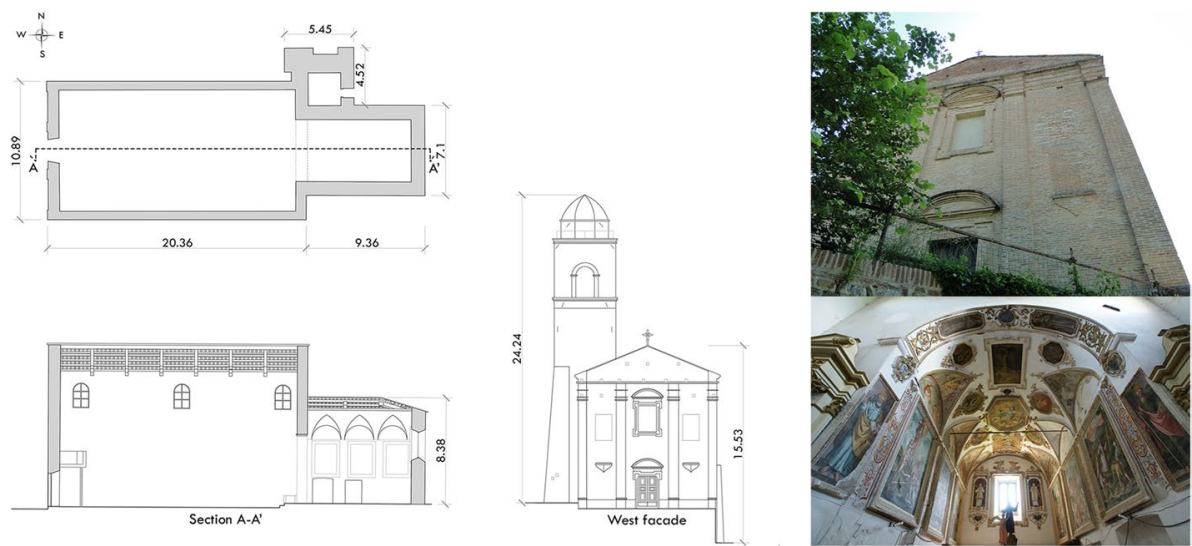

Fig. 2 Geometric configuration of San Francesco's church, Montefortino

\subsection{San Francesco church in Sarnano (Central Italy, Marche Region, Macerata province)}

The church goes back to the fourteenth century, and it was renovated in 1833; during this restoration, the church was elevated of about $4 \mathrm{~m}$ to make grant lighter, then a camorcanna barrel vault (it is featured with camorcanna, a type of vault made of a wood structure where reed mats are hanging and subsequently plastered) and ionic columns were added. Between 2014 and 2015 the church was restored again. The building has a unique nave of $11.26 \mathrm{~m}$ wide, $22.87 \mathrm{~m}$ long with a maximum height of $16 \mathrm{~m}$ and the tower has dimensions of $5 \mathrm{~m} \times 6.5 \mathrm{~m}$ and a height of $28 \mathrm{~m}$. On the south-west the church is connected with a little chapel, with a rectangular plant of $12.34 \mathrm{~m}$ length and $6.95 \mathrm{~m}$ width, the maximum height is of $11 \mathrm{~m}$ (see Fig. 3). The church has a timber roof. The bearing structure is made of solid bricks masonry.
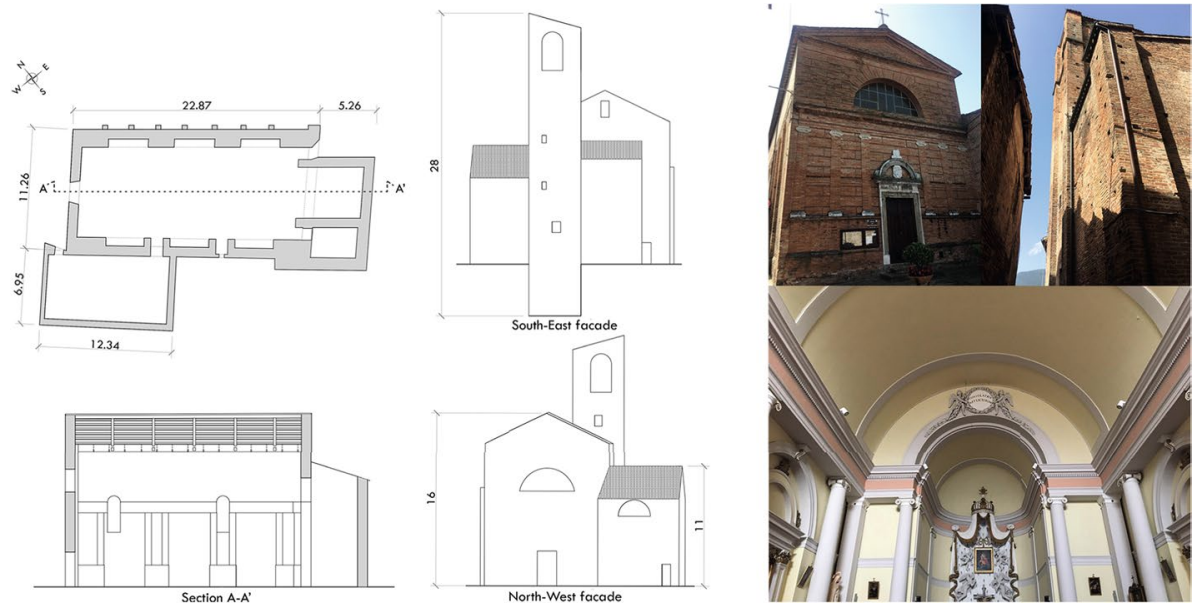

Fig. 3 Geometric configuration of San Francesco's church, Sarnano 


\subsection{Sant'Anna church in Camerino (Central Italy, Marche Region, Macerata province)}

It was built in the thirteenth century and erected in place of a church seriously damaged by a quake occurred in 1799. During the seismic event of Umbria-Marche in 1997, the church had a structural failure of the foundation; the retrofitting intervention was executed in 1999. The church has a unique nave of $8.53 \mathrm{~m}$ wide, $14.92 \mathrm{~m}$ long and with a maximum height of $16 \mathrm{~m}$. The thickness of the walls is in the range $0.7-0.8 \mathrm{~m}$. The bearing structure is made with disordered rubble stone masonry; the façade is covered by brick masonry. The triumphal arch separates the apse from the nave area. The arch is embedded in a brickwork board, with a circularly molded opening that is about $0.6 \mathrm{~m}$ thick. On one side there is an annex that has a rectangular shape with dimensions of $12.18 \mathrm{~m} \times 4.29 \mathrm{~m}$ and a maximum height of $8.46 \mathrm{~m}$ (Fig. 4).

\subsection{Sant'Antonio church in Ussita (Central Italy, Marche Region, Macerata province)}

The little church goes back to the seventeenth century; it has suffered serious damage after the 1997 seismic events. The church has a unique nave of $6.25 \mathrm{~m}$ wide, $10.96 \mathrm{~m}$ long and maximum height of $7 \mathrm{~m}$. The thickness of the walls is about $0.60 \mathrm{~m}$. The bearing structure is made of disordered rubble stone masonry. The triumphal arch isolates the nave region from the apse, and it is embedded in a brickwork divider, with a gothic mold. The nave is covered with wood roof and the apse has a light camorcanna vault. On one side there is an annex used as a sacristy. It has dimensions of $4.3 \mathrm{~m} \times 4.4 \mathrm{~m}$ and height of $3.6 \mathrm{~m}$ (Fig. 5).

\subsection{Madonna of Valcora Sanctuary in Fiuminata (Central Italy, Marche Region, Macerata province)}

It is located in the upper valley of the Potenza river, near the village of Fiuminata. The first documents date back the church between 1406 and 1435. The construction is simple, and
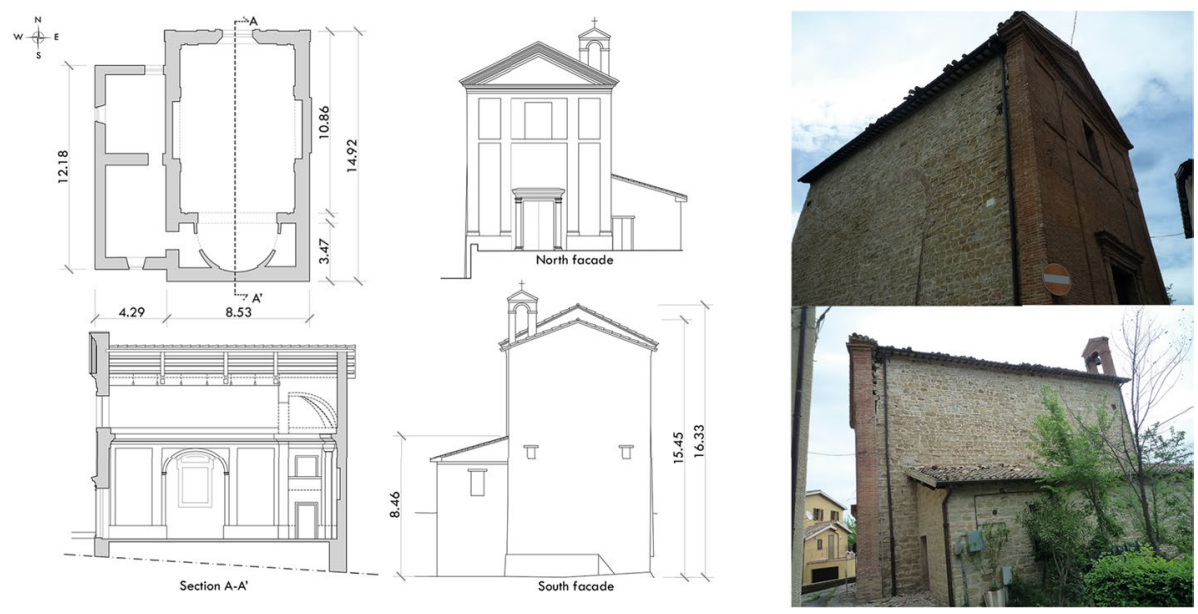

Fig. 4 Geometric configuration of Sant'Anna's church, Camerino 

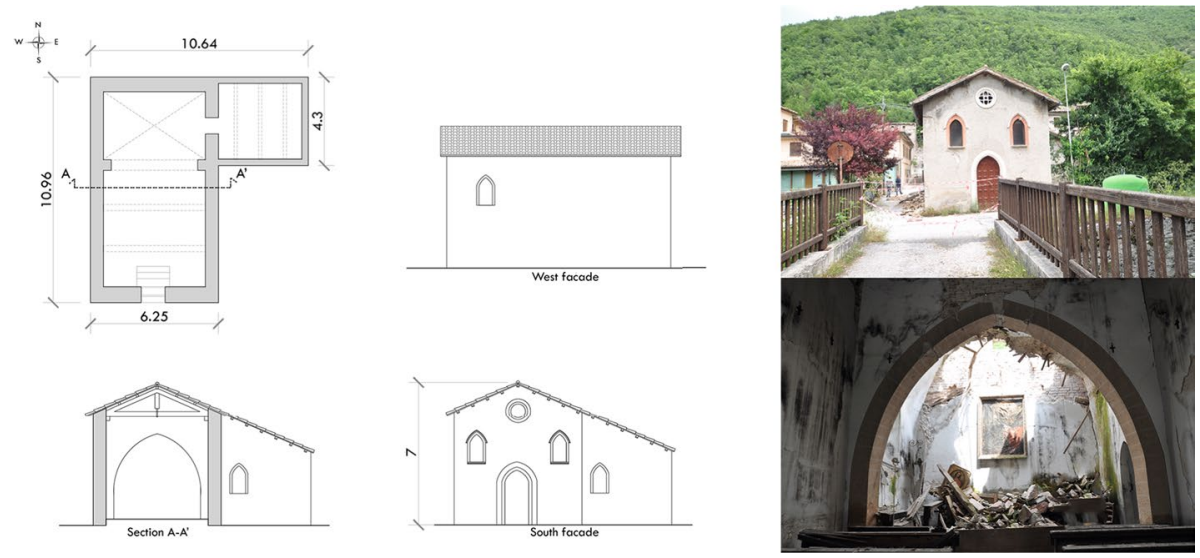

Fig. 5 Geometric configuration of Sant'Antonio's church, Ussita

it was extended in 1728. The church currently has a single nave of $9.16 \mathrm{~m}$ wide and $16.2 \mathrm{~m}$ long, with a gable roof. The thickness of the limestone walls ranges between 0.5 and $0.8 \mathrm{~m}$. The apse is the only part belonging to the original dwell and it dates to the fifteenth century (Fig. 6).

\section{Damage after the Central Italy earthquake of 2016}

The seismic sequence which striked Central Italy on 24th August 2016, 26th and 30th October 2016 and 18th January 2017 caused many injured, loss of lives and significant damages to most buildings belonging to the architectural heritage of the Italian regions of Marche, Lazio, Abruzzo, and Umbria. The mainshock occurred on 24th August at 3:36 am (local time) with an epicenter close to Accumoli (Rieti province) and with a magnitude $\mathrm{M}_{\mathrm{w}}=6$; it was followed, at $4.33 \mathrm{am}$, by an aftershock with an epicenter close to Norcia (Perugia province) and with a magnitude $\mathrm{M}_{\mathrm{w}}=5.5$. At the end of this first part of the
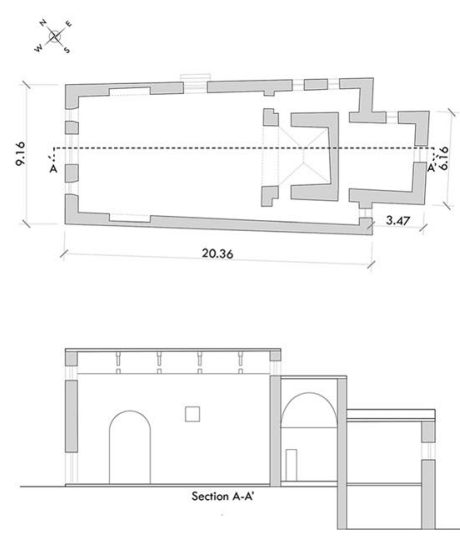
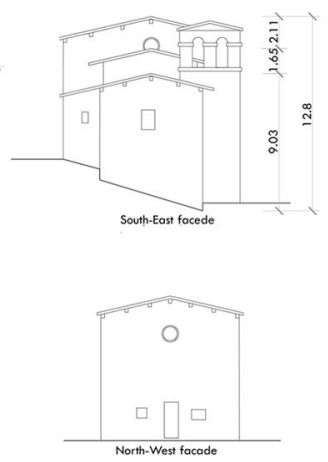

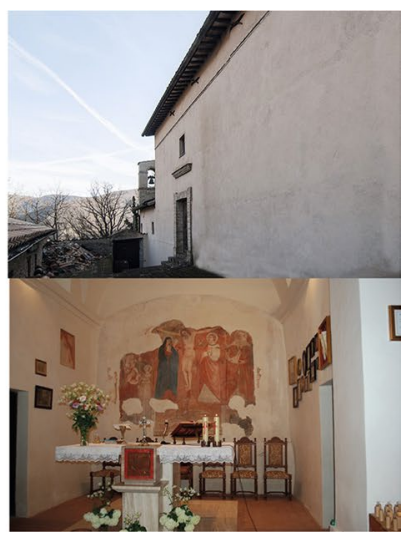

Fig. 6 Geometric configuration of Valcora's Sanctuary, Fiuminata 
seismic sequence, they were counted a total of 299 fatalities, 386 injured and about 4800 homeless (Italian Department of Civil Protection 2017; Fiorentino et al. 2018).

On 26th October, there were two strong aftershocks with 5.4 and $5.9 \mathrm{M}_{\mathrm{w}}$. The earthquake of 30th October, which happened at 7:40 am with $\mathrm{M}_{\mathrm{w}} 6.5$, is the main seismic shock regarding released energy occurred in Italy since the $M_{w} 6.9$ in 1980 of the Central Campania and central-northern Basilicata earthquake (also known as Irpinia earthquake). Finally, on 18th January 2017 a new sequence of four strong shocks of $M_{w}=5.4$ took place with epicenters located between the cities of Montereale, Capitignano and Cagnano Amiterno.

The authors conducted several field surveys on the churches here considered after the seismic sequence. On-site inspections are fundamental to collect information on the presence of local damage and its extension. In this paper, only a short description of the main damage observed in the five churches is provided, and some schematic drawings showing the main crack patterns are reported.

\subsection{Church of San Francesco in Montefortino (Central Italy, Marche Region, Fermo province)}

The major cracks appeared on the barrel vault of the apse, decorated with rich stuccos. The presence of a crack, between the bell-tower and the apse, suggest the possibility of the activation of bell tower rotation as also reported in the AEDES $^{\circledR}$ (Zuccaro and Cacace 2015) fast sheet. Some little cracks were developed between the façade and the walls of the nave, on the middle of façade, on the triumphal arch and the connection between the north wall and the bell-tower, Fig. 7.

\subsection{San Francesco church in Sarnano (Central Italy, Marche Region, Macerata province)}

It suffered minor damage; the cracks appeared on the light camorcanna vault of the nave in the middle and in correspondence with the façade, while other little cracks are visible on the triumphal arch, and on the light barrel vault of the apse, Fig. 8.

\subsection{Sant'Anna church in Camerino (Central Italy, Marche Region, Macerata province)}

It suffered significant damages mainly on the façade, where a diagonal crack is visible. It is provoked by the separation of the covering in brick masonry from bearing structure, thus the
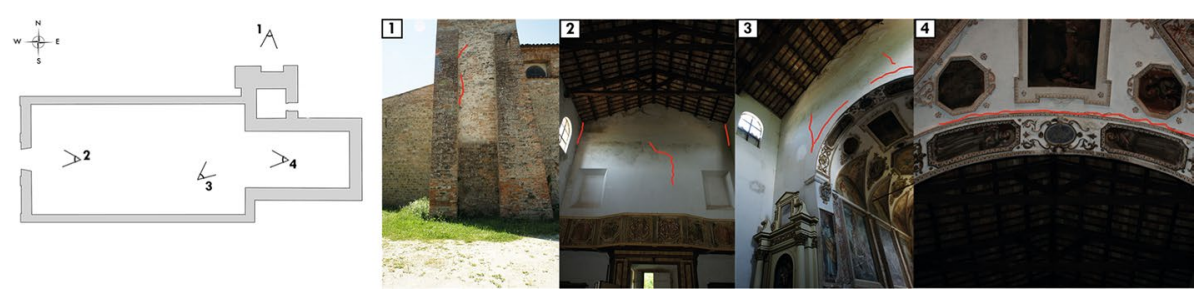

Fig. 7 Damage survey in the church of San Francesco in Montefortino after the Central Italy Earthquakes of 2016 

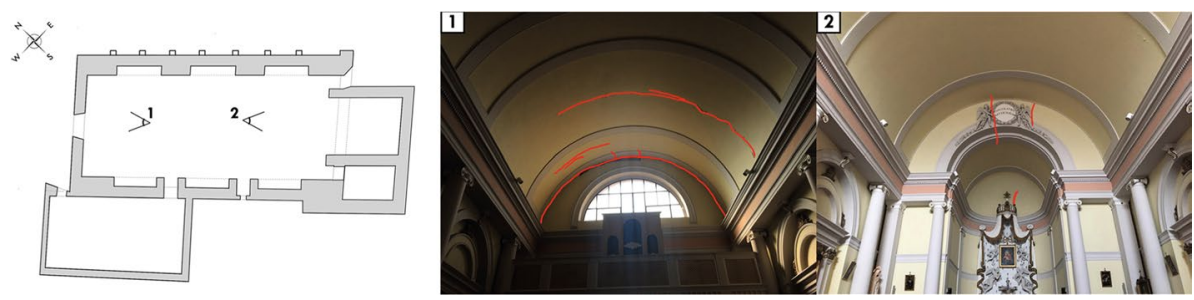

Fig. 8 Damage survey in the church of San Francesco in Sarnano after the Central Italy Earthquakes of 2016

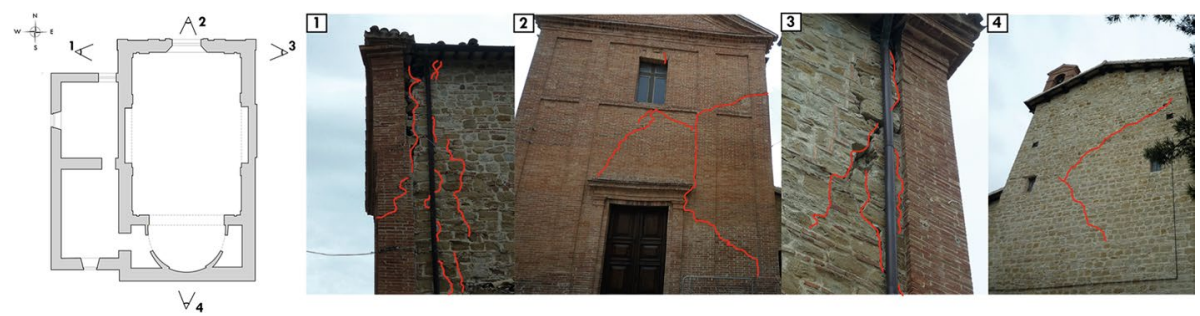

Fig. 9 Damage survey in the church of Sant'Anna in Camerino after the Central Italy Earthquakes of 2016

activation of the overturning of façade is evident, with cracks that appeared between it and the longitudinal walls of the nave. The south façade clearly shows diagonal cracks, Fig. 9.

\subsection{Sant'Antonio church in Ussita (Central Italy, Marche Region, Macerata province)}

It is the most damaged church among the five buildings analyzed since it is very near to the epicenter of 26th October 2016. It suffered extensive damages such as the collapse of the light vault on the apse and the bell-gable, and the massive cracking on the façade on the connection with the walls of the nave, in the central part under the rose window and correspondence of the two windows. Some cracks are also visible on the gothic arch, Fig. 10.

\subsection{Madonna of Valcora sanctuary in Fiuminata (Central Italy, Marche Region, Macerata province)}

The major crack appeared on the barrel vault of the apse. Minor cracks are widespread on all the complex. The cracks between the church and the bell-gable underline the possible activation of the overturning mechanism, Fig. 11.
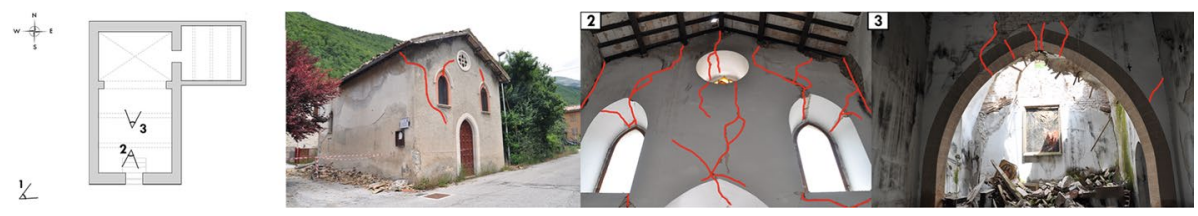

Fig. 10 Damage survey in the church of Sant'Antonio in Ussita after the Central Italy Earthquakes of 2016 


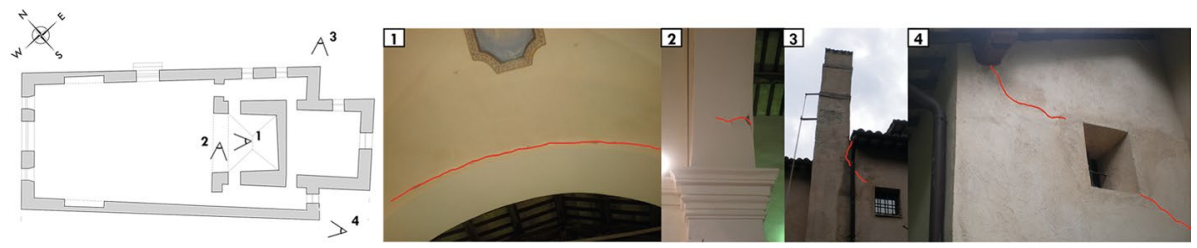

Fig. 11 Damage survey in Madonna of Valcora Sanctuary in Fiuminata after the Central Italy Earthquakes of 2016

\section{Distinct element method for historical masonry}

The FEM, which takes into account the numerical model as a continuous medium, is commonly used in practice (Betti et al. 2014; Valente and Milani 2016; Sarhosis et al. 2018), describing geometry and behavior with pre-defined finite elements. Although the behavior of a significant number of applications can be described using the FEM, the use of the DEM must be made when a discontinuous or intermittent means are investigated. Sets of distinct bodies constitute a discrete numeric model, and they can be characterized by deformable or stiff material. The interaction between individual discrete elements is labeled using contact laws (Lemos 2007). The laws that define contact between discrete elements can be evaluated in different ways (Asteris et al. 2015).

Among the various approach, a non-smooth contact dynamics model has been implemented in the LMGC90(C) open source software, within a non-smooth dynamics framework, with an implicit time integration, and implicit contact solvers [i.e., nonlinear Gauss-Seidel (NLGS), preconditioned conjugate gradient with projection (PCGP), etc.]. Furthermore, the applications with many interacting 3D bodies are reachable through parallel computing (shared or distributed memory); it is possible during computation to check the relevance of the analysis through some global indicators (convergence norm, quality of interaction laws computation, etc.).

In principle, the interaction between bodies, in DEM application is examined in the contact localized at point assumption, in which the normal and shear stress vector are functions of the relative displacement and velocity of the contacting objects. This simplification, however, still allows right accuracy using an enough contact points.

\subsection{NSCD for masonry structures modelling}

The NSCD method is based on a particular formulation of the motion equation, as firstly explained by Moreau (1988). The "non-smooth" regards to the specifics laws used to model mechanical systems with unilateral contacts and friction. The second-order dynamics is characterized by velocity jumps due to the impacts, with unilateral kinematic constraints on the position, which introduce to non-smoothness in time and space.

The non-smoothness in the interaction laws are written as multi-valued mappings between contact reactions and the relative velocity, in the framework of the NSCD method (Dubois et al. 2018). This method grants fairly large time steps. In fact, the multi-contact problem resolution consists in solving two groups of unknowns which are global ones, as kinematic space unknowns related to the blocks, and local ones as contact space unknowns, related to interactions, linked together thanks to kinematic and duality relationships. 

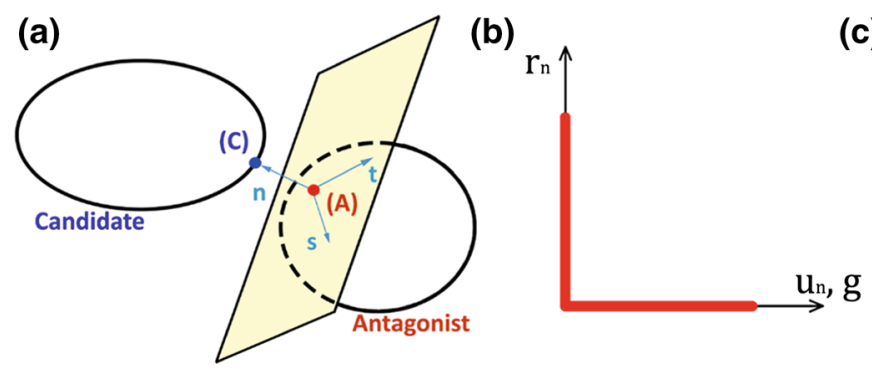

(c)

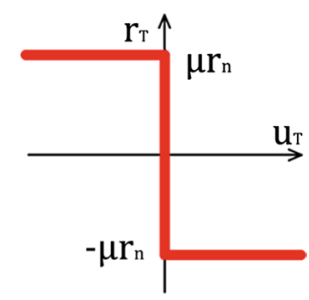

Fig. 12 Relation between candidate and antagonist in 3D space (a), Signorini's impenetrability condition (b), and friction à la Coulomb (c)

Moreover, the action and reaction law constrains contact forces between two blocks. In the NSCD method, to control the contact forces it is necessary to compute the interaction of the antagonist body $A$ on the candidate body $C$ (see Fig. 12) which is the force $r_{\alpha}$ acting at the contact point between these two bodies. At the contact, that is considered as punctual for simplifying, it is possible to set a local frame consisting of three vectors, in 3D model, including a normal vector $n_{\alpha}$ pointing from $A$ to $C$ and two tangential vectors $s_{\alpha}$ and $t_{\alpha}$, which define the tangential space by respecting this convention $s_{\alpha} \wedge t_{\alpha}=n_{\alpha}$. Moreover, the distance between body $\mathrm{A}$ and $\mathrm{C}$ along the normal direction is defined as the gap $g_{\alpha}$, which is positive for rigid bodies and there is not interpenetration between blocks.

Furthermore, it is required to correlate the local forces to the contribution of contact $\alpha$ to the resultant global force, using a linear mapping $\boldsymbol{H}_{\alpha}$, by the following equation:

$$
R_{\alpha}=\boldsymbol{H}_{\alpha}(q) r_{\alpha}
$$

where $\boldsymbol{H}_{\alpha}(q)$ is a mapping which contains the local information about contactors, where $q$ is the configuration parameter which can represent the discretized displacement or any generalized coordinates of the rigid motion. Additionally, it is possible to calculate the global resultant contact forces exerted on objects with the relation

$$
R=\sum_{\alpha} R_{\alpha}
$$

To analyse the velocity is used the same procedure. The relative velocity $u_{\alpha}$ at the contact point is defined for two bodies in contact by the following equation:

$$
u_{\alpha}=\boldsymbol{H}^{T}(q) v
$$

where $\boldsymbol{H}^{T}$ is the transpose of $\boldsymbol{H}, v$ is the time derivative of $q$, and $t$ is the time. The relative velocity is decomposed in a normal component represented by $u_{\alpha, n}$ and a tangential component $u_{\alpha, T}=\left(u_{\alpha, s}, u_{\alpha, t}\right)$. It should be noted that the derivative of the gap function $g$ is equal to the normal component of the relative velocity:

$$
t \rightarrow g_{\alpha}(t), \quad \dot{g}_{\alpha}=u_{\alpha, n} .
$$

During the evolution of the model, it is impossible to describe the acceleration as the usual second time derivative of the configuration parameter because it could be introduced shocks with multi-contact systems, which produce velocity discontinuities concerning time. Hence, the equation of motion will be written as

$$
\boldsymbol{M} d v=F(q, v, t) d t+d I,
$$


where $d t$ is the Lebesgue measure on $\mathbb{R}, \mathrm{d} v$ is a differential measure of velocity denoting the acceleration measure and $d I$ is a differential measure of impulse representing forces. The matrix $\boldsymbol{M}$ in the last equation is the mass matrix and the vector $F(q, v, t)$ is the vector of internal and external discretized forces acting on the system.

To determine the value of each component of $r_{\alpha}$, it is important to have additional information about contact forces. These data are primordial to complete the Eq. (5) and to describe the motion of the system. To simplify the writing, it is here considered the two-dimensional case, the $s$-components of $r_{\alpha}$, is disregard, the symbol $\alpha$ is omitted, and it is considered only $r_{n}$ and $r_{T}$ which represent the normal and tangential components of the force in the local frame respectively. The reaction force always has a positive normal component or at least equal to zero when the contact disappears. In fact, it is not possible to have penetration between bodies in the system, as mentioned above with the impenetrability of contact, and there is not attraction among contacting bodies. This contact behaviour is the so-called Signorini's condition or the first unilateral constraint:

$$
g \geq 0, r_{n} \geq 0 \text { and } g \cdot r_{n}=0 .
$$

Regarding the cohesive contact instead, even though it is not the case considered in this paper, the shifting can be applied to $r_{n}$ and $r_{T}$ and it assumes a value equal to zero if the contact is interrupted. For what concerns the case of Coulomb dry friction or the second unilateral constraint, it can be expressed by the equations below:

$$
\begin{cases}\text { if } & u_{T}=0, r_{T} \leq \mu r_{n} \\ \text { if } & u_{T} \neq 0, r_{T}=\mu r_{n}, u_{T}=-k r_{T}, k \geq 0\end{cases}
$$

As in (7), the main features are that the friction force lies in Coulomb's cone, with $r_{T} \leq \mu r_{n}$ and $\mu$ friction coefficient, and, in the slip phase, the friction resultant force is opposed to the sliding velocity with value equal to $\mu r_{n}$, when the sliding velocity $u_{T}$ is different from zero.

It is important to highlight that it is not necessary to manage explicitly the contact events in the time-stepping integration scheme, as in the case of the event-driven scheme. The time subdivision is done on intervals $\left[t_{i}, t_{i+1}\right]$ of length $h$ and it is fixed, consequently it is possible to deal with a great number of discontinuities during one-time step, and the contact problem is solved over the range in terms of measures of this interval and not in a point-wise way. Thus, the equation is integrated on each time step, which involves to

$$
\left\{\begin{array}{l}
\boldsymbol{M}\left(v_{i+1}-v_{i}\right)=\int_{t_{1}}^{t_{i+1}} F(q, v, t) d t+I_{i+1}, \\
q_{i+1}=q_{i}+\int_{t_{1}}^{t_{i+1}} v(t) d t,
\end{array}\right.
$$

where the variable $v_{i+1}$ denotes the approximation of the right limit of the velocity at the time $t_{i+1}$, and $\mathrm{q}_{i+1} \approx \mathrm{q}\left(\mathrm{t}_{i+1}\right)$. For the impulse $I$, it is integrated the measure $d I$ over the time interval $\left[t_{i}, t_{i+1}\right]$

$$
I\left(\left[t_{i}, t_{i+1}\right]\right)=\int_{\left[t_{i}, t_{i+1}\right]} d I \cong I_{i+1}
$$

Afterward, it is introduced the $\theta$-method as time-integration algorithm, that is an implicit scheme and it remains between 0.5 and 1 for the stability condition of the scheme, to 
approximate the two integrals of the system introduced before in (8), which leads to the following equation:

$$
\left\{\begin{array}{l}
\int_{t_{1}}^{t_{i+1}} F(q, v, t) d t=h \theta F\left(q_{i+1}, v_{i+1}, t_{i+1}\right)+h(1-\theta) F\left(q_{i}, v_{i}, t_{i}\right), \\
q_{i+1}=q_{i}+h \theta v_{i+1}+h(1-\theta) v_{i} .
\end{array}\right.
$$

Hence, it is important to highlight the fact that to investigate the ancient masonry buildings it is necessary to do some observations on the NSCD method used here, which relies on modelling simplifications. The main assumption is that the blocks are stiff. Moreover, we add a perfectly plastic impact law to the contacts between blocks, in addition to the Signorini's impenetrability condition, i.e., Newton law with restitution coefficient equal to zero, which involves no bounces after collisions. According to this, there are valuable advantages regarding the contribution of impacts to the computational complexity, that is modest since they are modelled in a very basic and simple way, and about the perfectly plastic impact, which dissipates energy. Actually, regarding the integration, the dissipation improves the stability of the numeric computation and, from an engineering perspective, it is represented by the material failures and cracks of bricks after the impacts. Furthermore, friction also contributes to dissipation, while damping is not treated here, even though it is an essential element of continuum models

\section{The modelling of the churches}

Complete models have been formed to better understand the influence of seismic mechanisms within the structures, with the aid of an external program used to generate complex configuration without approximations on the geometries. The models (Fig. 13) were designed from the smallest level measured for each church, considering the presence of different levels for some basement due to the natural slope of the land. Attention is given to modelling the connections between the various elements orthogonally arranged, trying to have the greatest fidelity with the reality of the wall textures.

The blocks are represented as convex polyhedral in 3D with each face being a planar convex polygon with rectilinear edges. Here there is mainly face to face contact with four contact points as reported in the enlargements in the Fig. 13. In general, the masonry units (rigid body discretisation) are regularized and expanded to include the thickness of the joints. Because of this procedure, the bricks units are modelled by blocks of different sizes, based on dimensions and characteristic of walls, and the joints have zero thickness. The values adopted for masonry mass density are taken in agreement with the real structures as also suggested by the (Ministero dei Lavori Pubblici e dei Trasporti 2009). The friction coefficient usually varies between 0.3 for old and/or not good masonry, to 0.8 for brand new or repointed masonry (Vasconcelos and Lourenço 2009). Furthermore, it is important to underline that in real old masonry buildings, the degradation of the mortar over time contributes to deteriorating the friction coefficient. As a first attempt, we assume the value $\mu=0.5$ for the interface block/block, and $\mu=0.9$ for the interface block/foundation to observe, mainly, the dynamics of the churches without the structure-foundation interaction. This value, which is kept constant in all simulations, in our opinion provides a good 

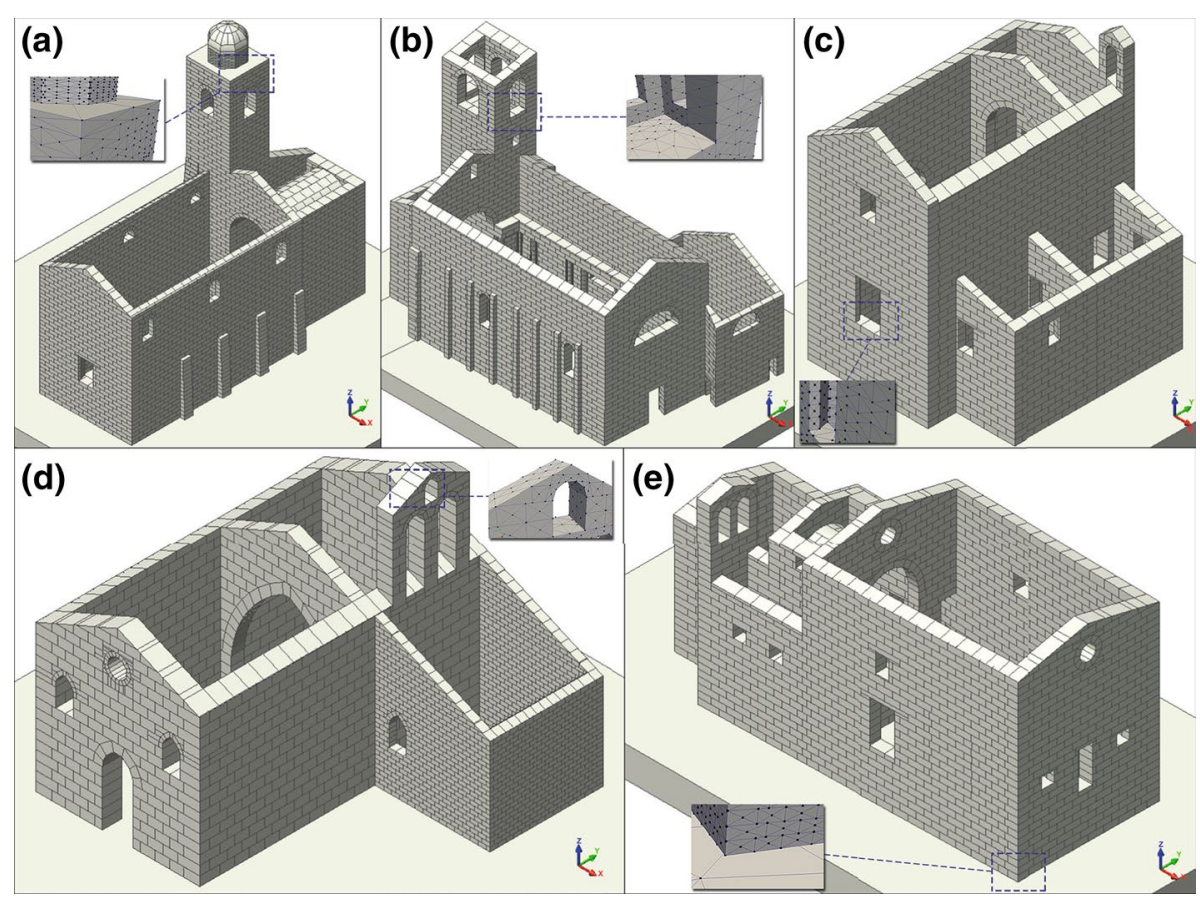

Fig. 13 The numerical models with the NSCD method for San Francesco's Church in Montefortino (a), San Francesco's Church in Sarnano (b), Sant'Anna's church in Camerino (c), Sant'Antonio's church in Ussita (d), Valcora's Sanctuary in Fiuminata (e)

approximation in the light of the retrofitting interventions that the churches had following the Umbria-Marche earthquake in 1997.

Initially, gravity load has been assigned to the system. Then, several simulations were performed by varying the ground acceleration of the basement: the excitations of real earthquakes are applied to the basement, and the damage due to real earthquakes is investigated. In particular, the analyses were carried out using the horizontal and vertical components of the three main shocks recorded during the Central Italy seismic sequence of 2016-2017, with the aim to analyze the damaged caused by the seismic activity. Considering that there are no available recordings of the accelerations and velocities in all villages where the churches are located, it was necessary to use those registered in the epicenters of the three main shocks: (1) 24th August 2016 Amatrice with $\mathrm{M}_{\mathrm{L}}=6.0$ and $\mathrm{M}_{\mathrm{W}}=6.0$ (AMT station in Italian Accelerometric Archive (ITACA)), (2) 26th October 2016 Campi with $\mathrm{M}_{\mathrm{L}}=5.9$ and $\mathrm{M}_{\mathrm{W}}=5.9$ (CMI station in ITACA), (3) 30th October 2016 Forca Canapine $\mathrm{M}_{\mathrm{L}}=6.1$ and $\mathrm{M}_{\mathrm{W}}=6.5$ (FCC in ITACA). The comparison between the recorded accelerations is reported in Fig. 14. In Table 1 are reported the characteristics of the seismic events used, where (Kadas et al. 2011):

- $\mathrm{R}_{\mathrm{jb}}$, is the Joyner-Boore distance, known as the smallest spacing from the site to the surface projection of the rupture surface;

- $\mathrm{R}_{\text {rup }}$, is the shortest distance between the site and the rupture surface;

- $\mathrm{R}_{\mathrm{epi}}$, is the distance estimated by the geometric swap. 
(a)
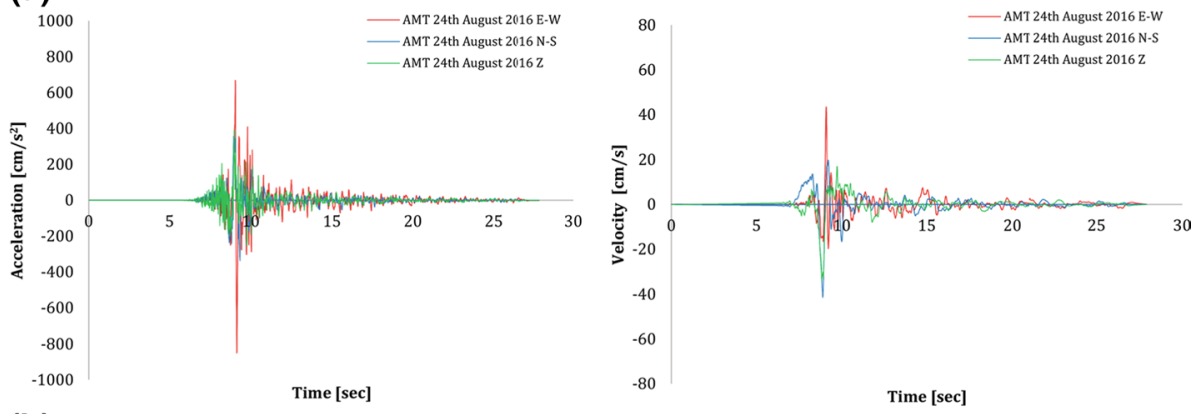

(b)
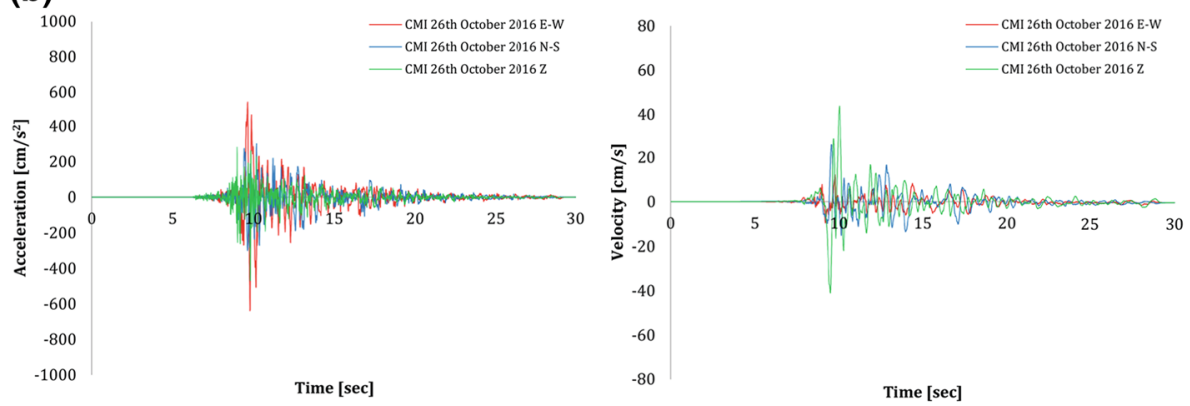

(c)
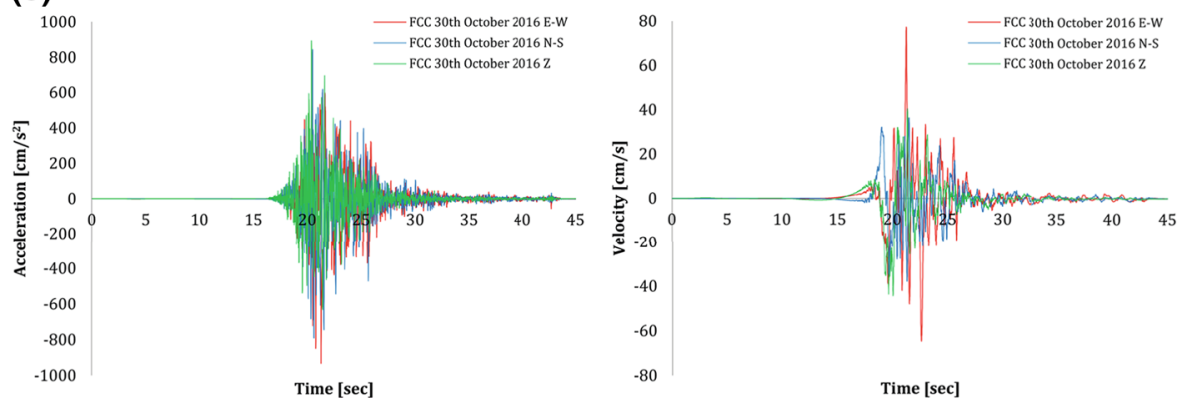

Fig. 14 The components of the three main ground accelerations and velocities recorded for: the 24th August 2016 Earthquake in the station of Amatrice (AMT) (a), the 26th October 2016 Earthquake in the station of Campi (CMI) (b), and the 30th October 2016 Earthquake in the station of Forca Canapine (FCC) (c)

\section{Numerical results}

The solving procedure adopted by NSCD method is particularly effective in the simulation of the progressive development of damage mechanisms, as the block movements induced by separation and sliding along the joints can be strictly followed, until the total collapse of the masonry structures. The dynamic analyses in the time domain with all results and clear pictures of damages caused by real earthquakes are reported hereafter. 


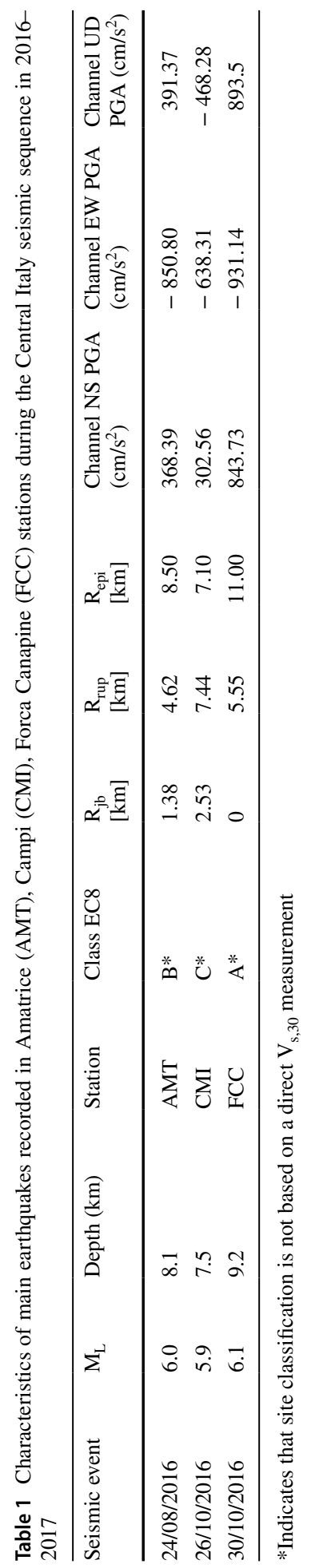



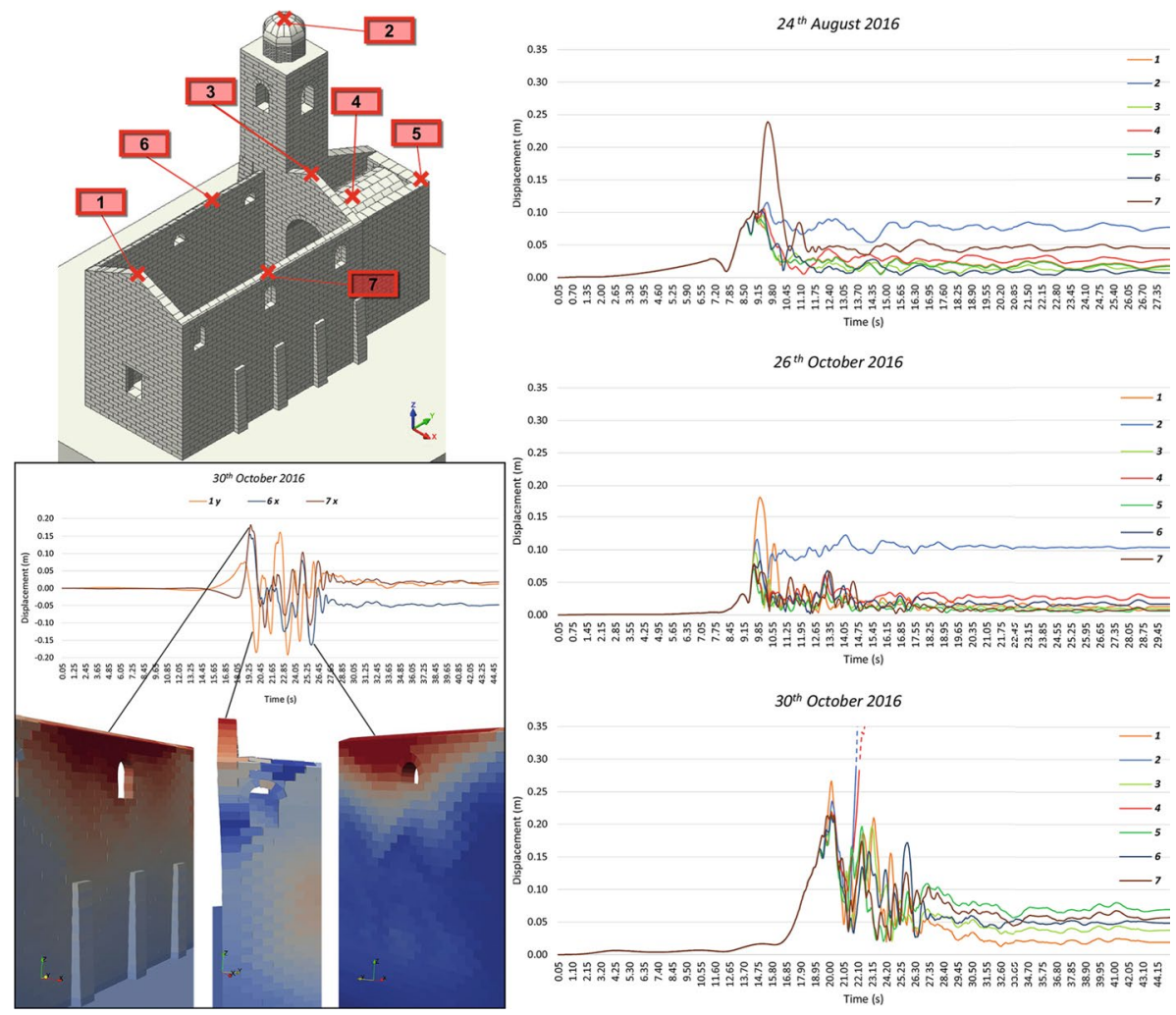

Fig. 15 Displacements time histories of different control nodes for the Church of San Francesco in Montefortino (FM) for the three main shocks of Central Italy seismic sequence of 2016

\subsection{Church of San Francesco in Montefortino (Central Italy, Marche Region, Fermo province)}

The main results in terms of Time Histories (THs) are reported in Fig. 15 for different control points on the top of the Church and of the tower. In general, it is quite clear to observe that the earthquake of 30th October 2016 first produces the major displacements on the church and belfry, then the main damages.

Comparing the control points \#1 and \#3, Fig. 15, namely those on the main façade and on the triumphal arch, at varying of the main shocks we can observe that the resultant displacement of \#1 is bigger than \#3 for the shocks of 24th August and 26th October but becomes comparable with the shock of 30th October, and this confirms what happened in situ, i.e., that the major damages were associated with the main seismic action, where also some residual displacement is noticeable. In fact, comparing the enlargement of Fig. 15 with Figs. 16, 17, and 18, we see an evident out-of-plane displacement of the main façade (with more significant displacement on the top of it) and an in-plane action of the triumphal arch, and incidentally, confirm the real damages in Fig. 7.

Comparing the TH of points \#6 and \#7 in Fig. 15, and the numerical damage in Figs. 16 and 17 , we can observe a different behavior of the two walls of the nave: with the shock of 24th August the point \#7 reached immediately for $t \sim 9.65 \mathrm{~s}$, i.e., when maximum value 



Fig. 16 Damages of the Church of San Francesco in Montefortino (FM) under the earthquakes of 24th August 2016 (a), 26th October 2016 (b), and 30th October 2016 (c)
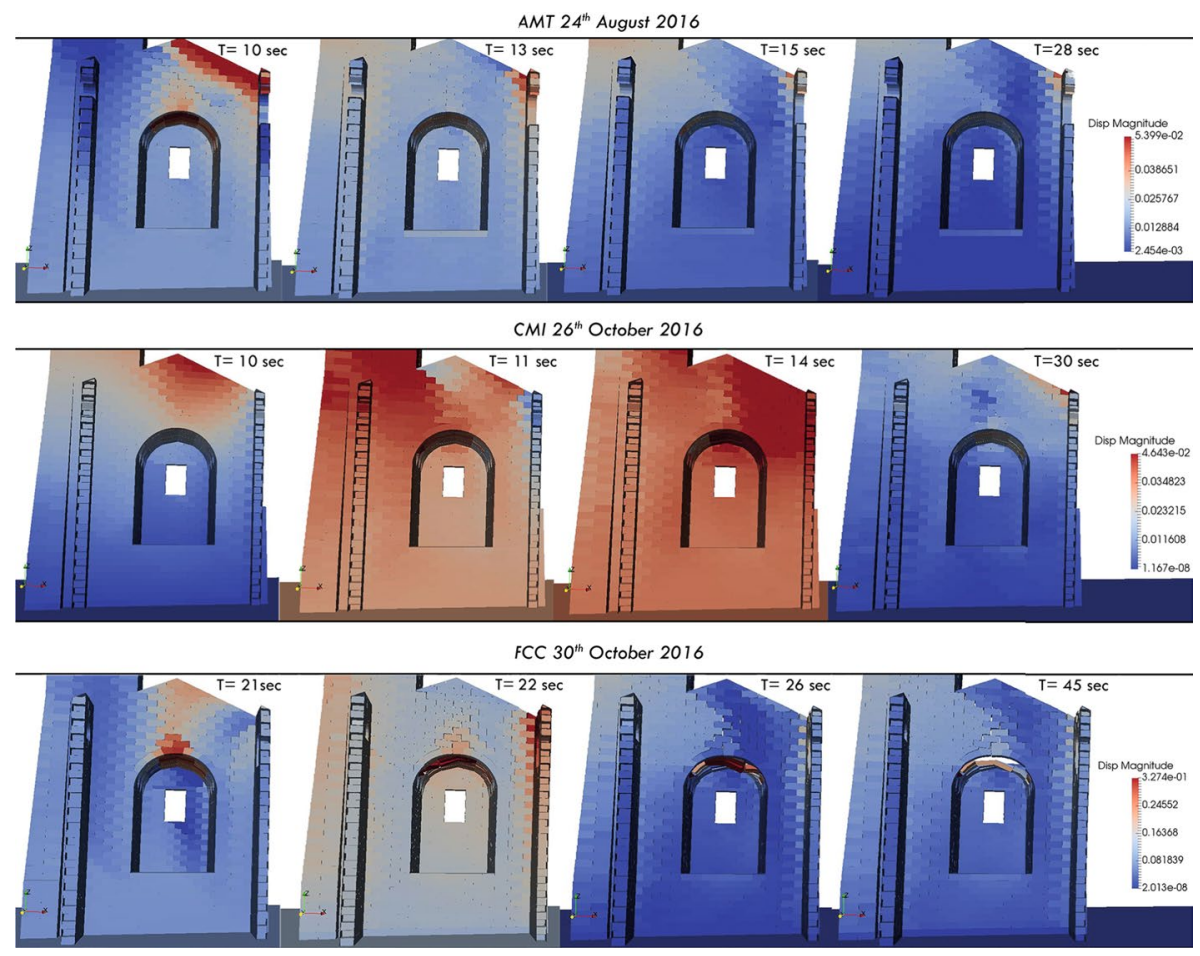

Fig. 17 View of mechanism in the triumphal arch and in the vault of San Francesco in Montefortino (FM)

of the velocity in $N-S$ direction is attained (Fig. 14), the displacement of about $24 \mathrm{~cm}$. The displacements are comparable between the two points for both 26th and 30th October earthquakes, in the last with a residual displacement of about $5 \mathrm{~cm}$ at the end with evident misalign of the block in the out-of-plane direction of the main walls of the nave.

On the belfry, namely point \#2, no evident damages are noticeable with the first two shocks, but a clear collapse is observable in Figs. 16, 17 and 18 with the earthquakes of 30th October and, with right approximation due to the distance between Montefortino and the epicenter, as we once again observed in situ, where lower intensity of the earthquake was detected, and then minor damages on the belfry are observable. The same situation 

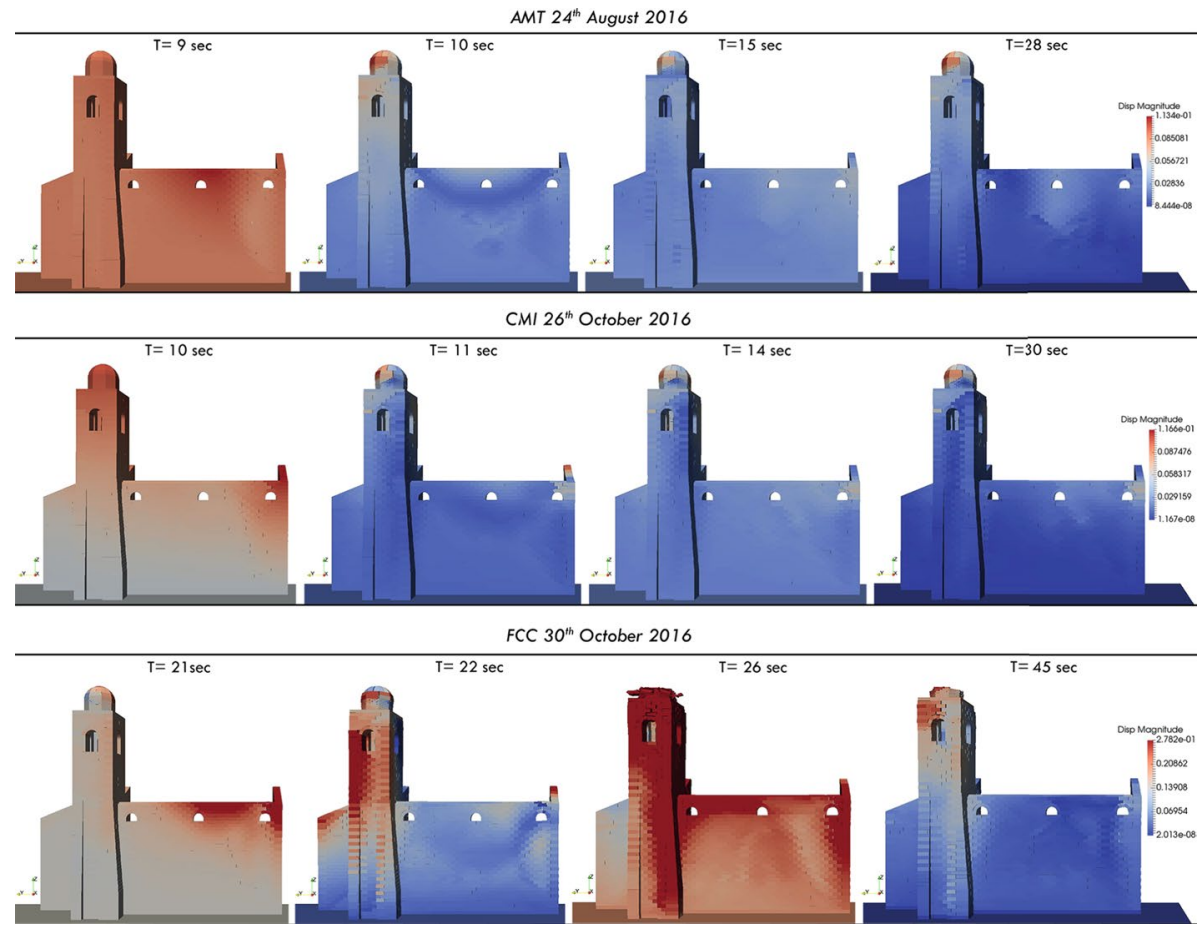

Fig. 18 Failure mechanism of the bell-tower of San Francesco in Montefortino (FM)

occurred on the vault on the apse, namely point \#4, where an evident collapse is noticeable with the main shock of the sequence, and again the damage is comparable to the real one reported in Fig. 7.

Finally, it is important to point out the fact that at varying of the event, for the church of Montefortino, the same collapse mechanisms are always observable. This highlights how the activation of typical vulnerabilities can certainly be identified with sophisticated analyzes giving a deep insight into the seismic vulnerability of the church.

\subsection{Church of San Francesco in Sarnano (Central Italy, Marche Region, Macerata province)}

The main results of dynamic analyses in terms of THs are reported in Fig. 19, for the three main shocks, showing higher values of displacement for the control points of the belfry (\#2) and the triumphal arch (\#3) for all the considered earthquakes.

Looking at Fig. 20, a clear picture of the damage at the end of the shocks is visible, confirming the presence of extensive damage of the triumphal arch and of the bell tower, also displayed by Figs. 21 and 22. In the TH of 24th August, the activation of out-of-plane mechanisms related to points \#6 and \#7 of the annex are noticeable, which turns into an overturning collapse during the 30th October event (see \#7 of south-west façade of the annex) as shown in Fig. 20. These activations are not so evident with the 

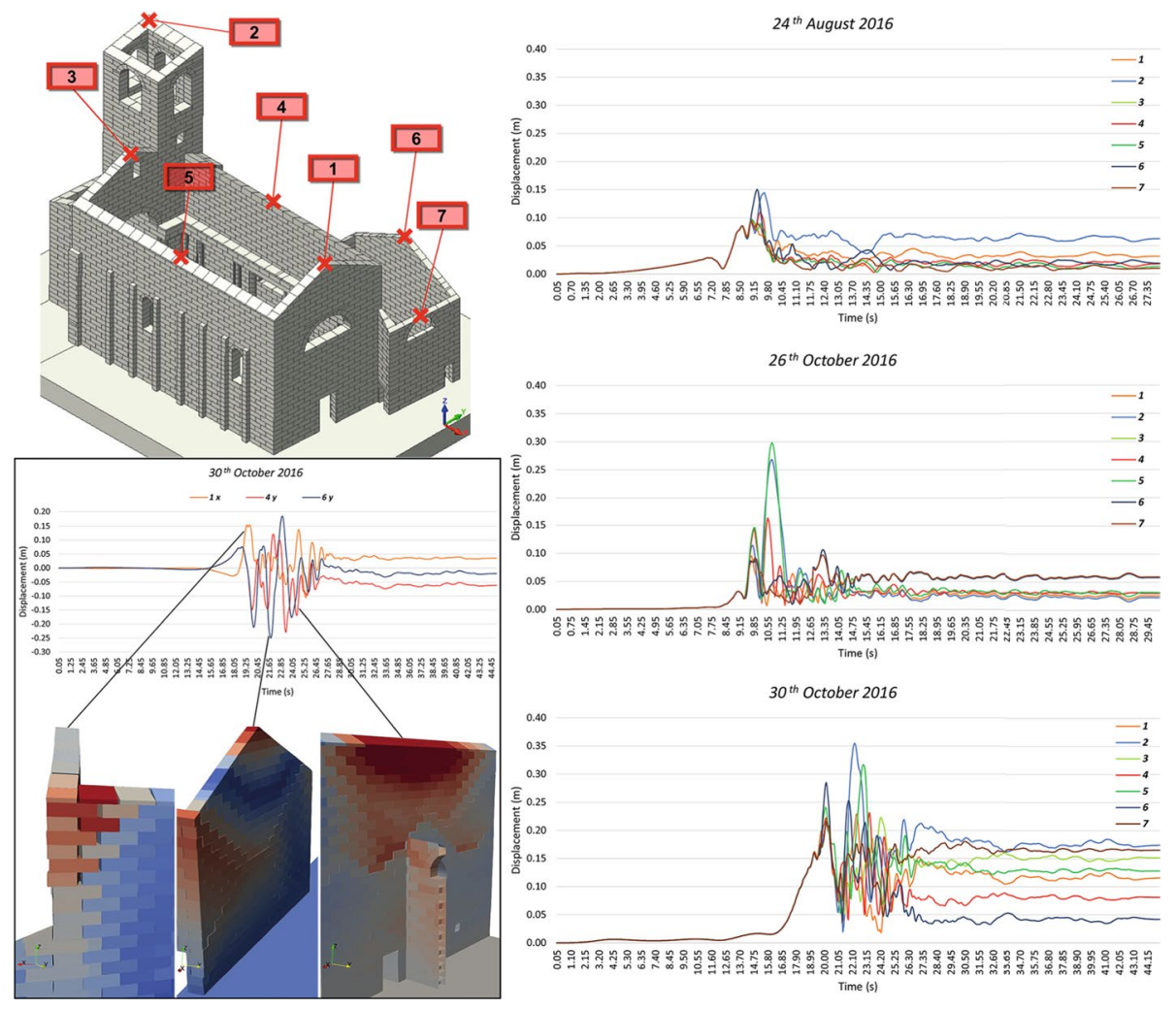

Fig. 19 Displacements time histories of different control nodes for the church of church of San Francesco in Sarnano (MC) for the three main shocks of Central Italy seismic sequence of 2016

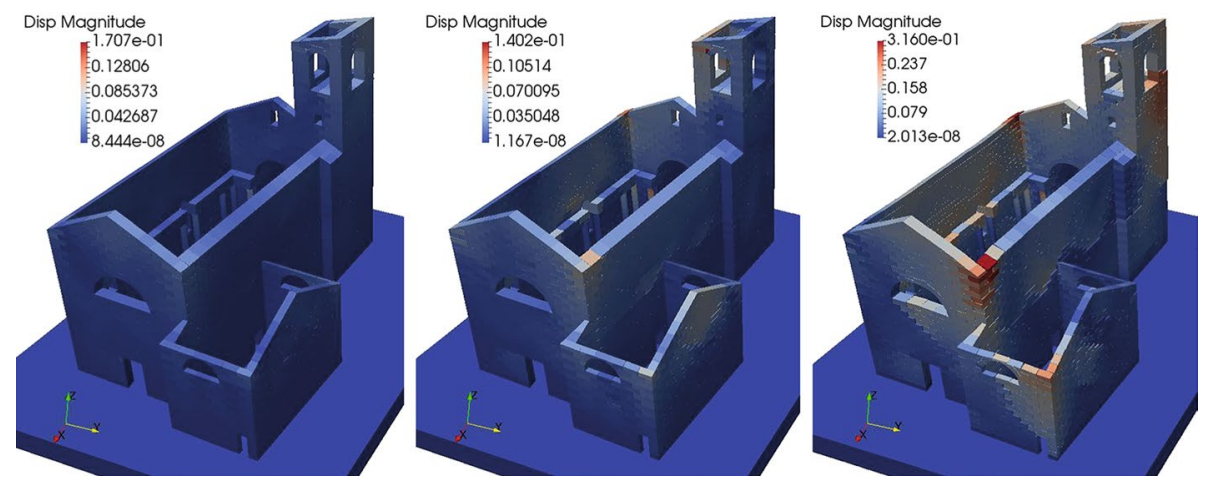

Fig. 20 Damages of the Church of San Francesco in Sarnano (MC) under the earthquakes of 24th August 2016 (a), 26th October 2016 (b), and 30th October 2016 (c) 



Fig. 21 Shear mechanisms in the triumphal arch of San Francesco in Sarnano (MC)

shock of 26th October, even if the residual displacement of \#7 is about $6 \mathrm{~cm}$. Except for the 24th August, the point on the north-east wall of the nave (\#5) also shows a high displacement, mainly due to the activation of an out-of-plan mechanism as can be observed from the Fig. 21. Finally, the main façade (\#1) always shows a high displacement for all earthquakes leading to an out-of-plane mechanism, clearly visible in the enlargement of Fig. 19 with a significant sliding between the blocks, and this coincides once again with what is observed in reality and reported in Fig. 8.

\subsection{Church of Sant'Anna in Camerino (Central Italy, Marche Region, Macerata province)}

The main results of the nonlinear dynamic analyses with the NSCD method are reported in Fig. 23 in term of TH for the three-main earthquakes used as a reference, and at the end of the simulations in Fig. 24. Starting from the 24th August earthquake, it is possible to observe that the bell-gable (namely the control point \#2) is the most involved part of the church with a maximum reached displacement of about $29 \mathrm{~cm}$ in correspondence of the main jump of the velocity (see Fig. 14a). Comparing the THs of the main façade 

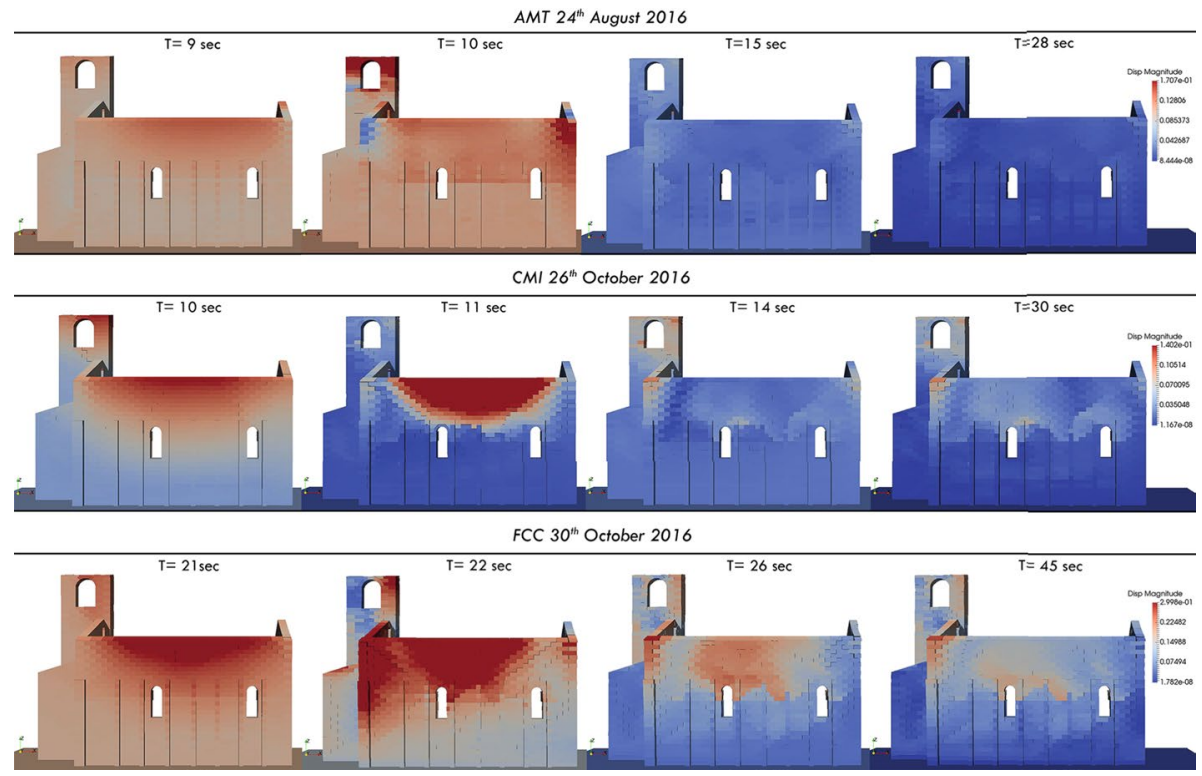

Fig. 22 Failure mechanism of the bell-tower and triumphal arch of San Francesco in Sarnano (MC)

(\#1), of the triumphal arch (\#4) and of rear façade (\#3) we can observe the same displacement, with a residual value of about $3 \mathrm{~cm}$ at the end of the shock. The bell-gable (\#2) is subjected to large displacements to which correspond high damage but does not apparently manifest collapses (Fig. 24). Looking to Fig. 25, it is possible to observe the activation of the overturning mechanism of the main façade due to a not proper interlocking between the block, and this is comparable with the real damage reported in Fig. 9. Observing the three main longitudinal walls of the church, namely the walls containing control points \#5, \#6 and \#7, residual displacements are always observable, and from Fig. 24 and Fig. 26, the starting of a little out-of-plane mechanism is visible in the upper part of the wall of the nave due to the pushing of the triumphal arch at last.

For the earthquake of the 26th October, a quite similar behavior is observed except for the control points \#1 and \#2, which have an opposite behavior compared to what we saw before. With the first jump of the velocity (see Fig. 14b) we can see an increase on the displacement of the main façade (\#1), that corresponds to a more visible overturning mechanism in Fig. 25 to which follows an increase in the vertical seismic action that strongly stresses the bell-gable until it collapses. Then a general higher deformation along the church is noticeable if compared to the previous case, with some more evident misalignment of the blocks in the out-of-plane direction in the left upper part of the wall of the nave (Fig. 26), corresponding to the connection with the triumphal arch.

With the main shock of the seismic sequence of the Central Italy earthquake, namely the 30th October, more evident mechanisms due to higher values of displacement in all the control points (see Fig. 25) are noticeable. The façade, plotted with the control point \#1, has a residual displacement of $25 \mathrm{~cm}$ with a quite clear activation of the overturning mechanism (see Figs. 25 and 26). The same consideration is valid for the bell-gable and the triumphal arch, namely \#2 and \#4, which denoted in Fig. 23 a clear activation of the in-plane mechanism with a downward sliding of the key ashlar and an 

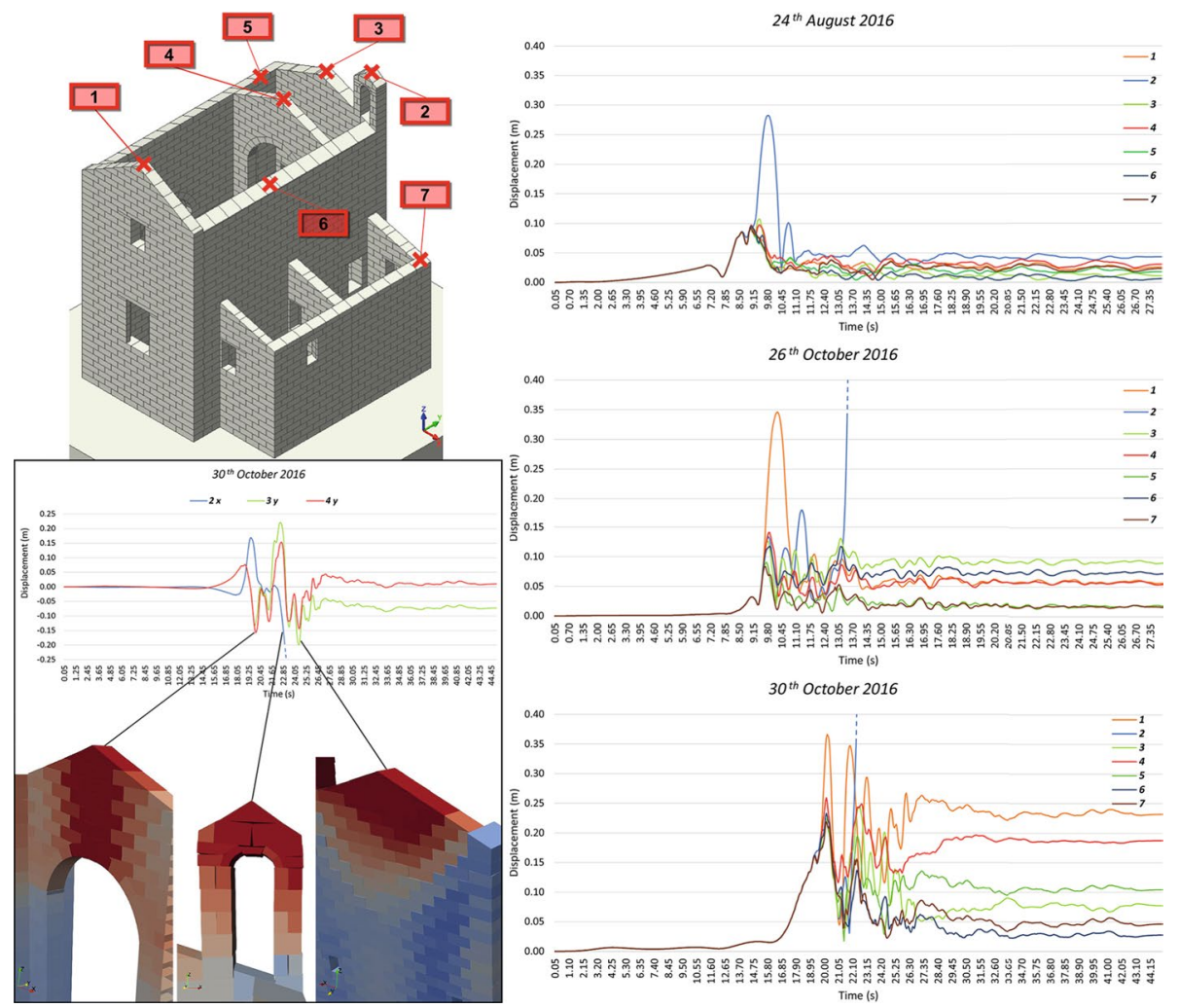

Fig. 23 Displacements time histories of different control nodes for the Church of Sant'Anna in Camerino (MC) for the three main shocks of Central Italy seismic sequence of 2016
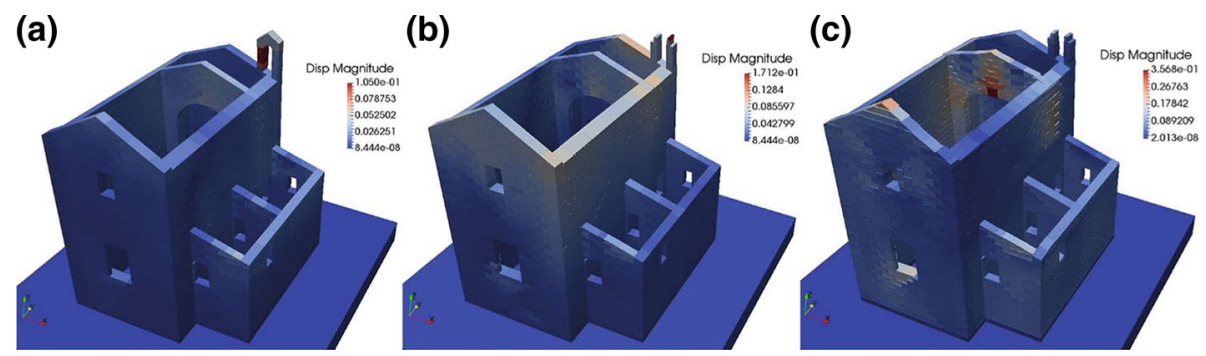

Fig. 24 Damages of the Church of Sant'Anna in Camerino (MC) under the earthquakes of 24th August 2016 (a), 26th October 2016 (b), and 30th October 2016 (c)

out-of-plane mechanism with a significant displacement in the middle. Comparing the control points \#5 and \#6, namely those of the walls of the nave, it is clearly visible the effect of the pushing of the triumphal arch which increases first the displacement and then the residual deformation of \#5 respect to \#6. Furthermore, there are no activations of clear mechanisms in the annex (see \#7 in Fig. 23), but only a trigger of a detachment between it and the nave. Finally, also in this case, the bell-gable (see \#2 in Fig. 23) is 

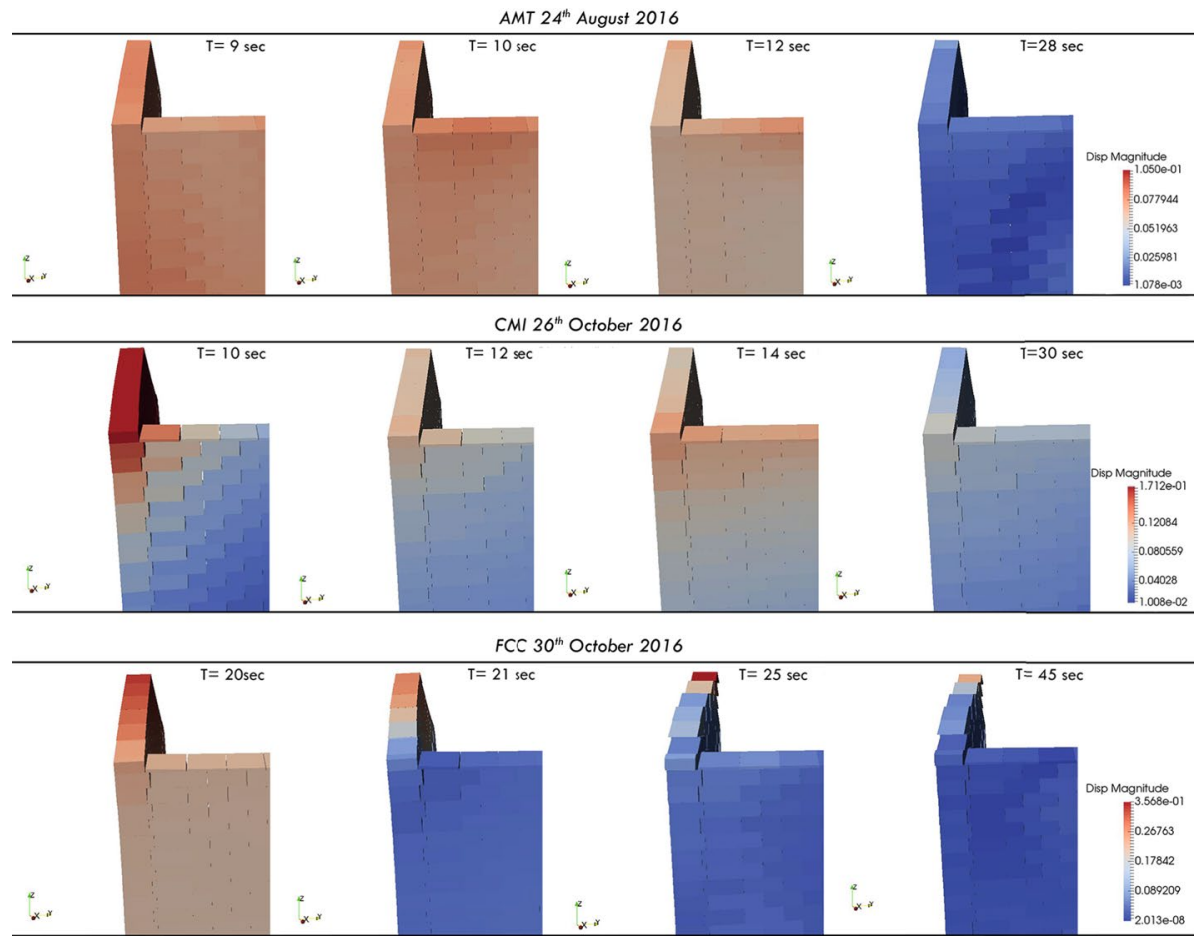

Fig. 25 Failure mechanism of the facade of Sant'Anna in Camerino (MC)

most vulnerable part of the church, as well as the façade, as also demonstrated by the real damages in Fig. 9.

\subsection{Church of Sant'Antonio in Ussita (Central Italy, Marche Region, Macerata province)}

The Sant'Antonio's Church is the most damaged one of the analyzed stock of "Apennine churches." The THs of different control points in the top of the main parts are reported in Fig. 27. Comparing the points \#1, \#2 and \#4, respectively on the main and rear façades, and on the triumphal arch, a global out-of-plane overturning and in-plane shear actions, with apparent failure under the rose window and the two classical windows, are clearly visible in Figs. 28, 29 and 30. In particular, with the shock of the 24th August, only a first activation of these mechanisms is visible with a residual displacement (less than $5 \mathrm{~cm}$ ) in all parts of the church at the end of the TH, Fig. 27.

The same considerations should be applied to the shock of 26th October 2016, where the maximum displacement attained to the various parts are the same of the previous analyses, confirming the high vulnerability of the main façade and of the triumphal arch where the first vertical cracks appeared, due to the activation of out-of-plane and in-plane mechanisms respectively. Looking at control point \#3, a clear overturning mechanism is activated, and a first evident detachment due to the lack of firm connections between the wall of the annex and the nave is also visible (see Fig. 30). 

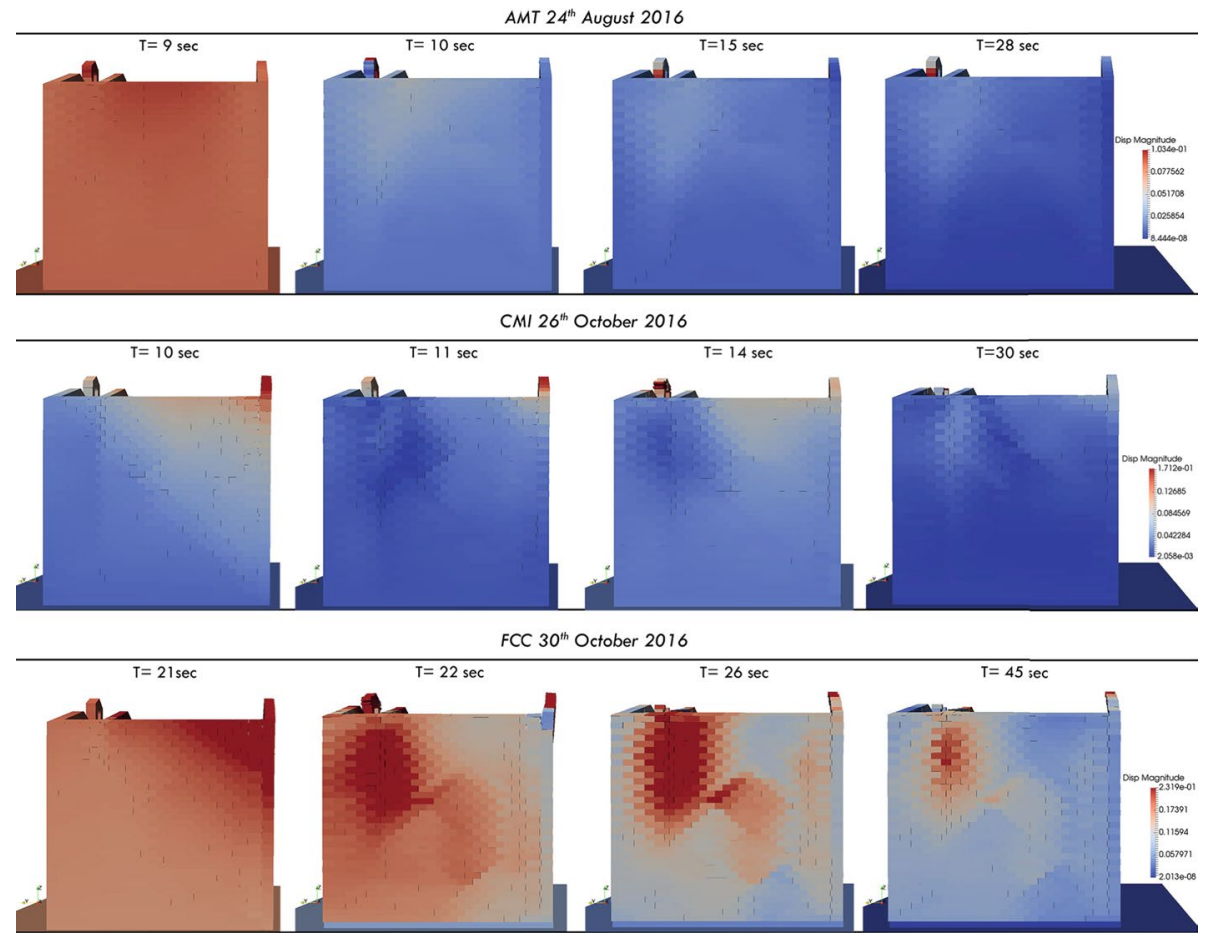

Fig. 26 Failure mechanism of the façade, wall, and steeple of Sant'Anna in Camerino (MC)

With the TH of 30th October 2016, the same mechanisms are always activated but, due to a very high seismic intensity, the displacements are more significant than the previous ones, which led to the collapse of several portions of the façade and the annex walls (see the enlargement of Fig. 27). With this TH, not only the activation but also the evolution of the damage of the main façade is visible from Figs. 28 and 29, confirming once more the cracking path reported in Fig. 11. The very high values of displacement $(>25 \mathrm{~cm})$ of the points \#4 and \#2 from Fig. 27 which in most of the cases are also in anti-phase, confirm the collapse of the roof of the apse for the possible loss of support. The difference in terms of damage level is again due only to the different intensity between the epicenter and the area where the church stands. From Fig. 27 it is possible to observe in addition to the overturning mechanisms of the annex, also the loss of straightness of the walls of the nave which is a consequence of the active involvement of the walls in the out-of-plane direction. This deformation is visible also in Fig. 27, where at the end of the TH, a residual displacement bigger than $5 \mathrm{~cm}$ is present in all the wall.

\subsection{Sanctuary of Madonna of Valcora in Fiuminata (Central Italy, Marche Region, Macerata province)}

In Fig. 31 are plotted the THs of six control points chosen on the top of Valcora sanctuary, for the three main shocks. This church reported a widespread crack in all its parts. Observing the $\mathrm{TH}$ of the 24th August it is noticeable that in correspondence to the first jump of velocity most of the points show the same displacement (control points \#1, \#4, \#5, and \#6), 

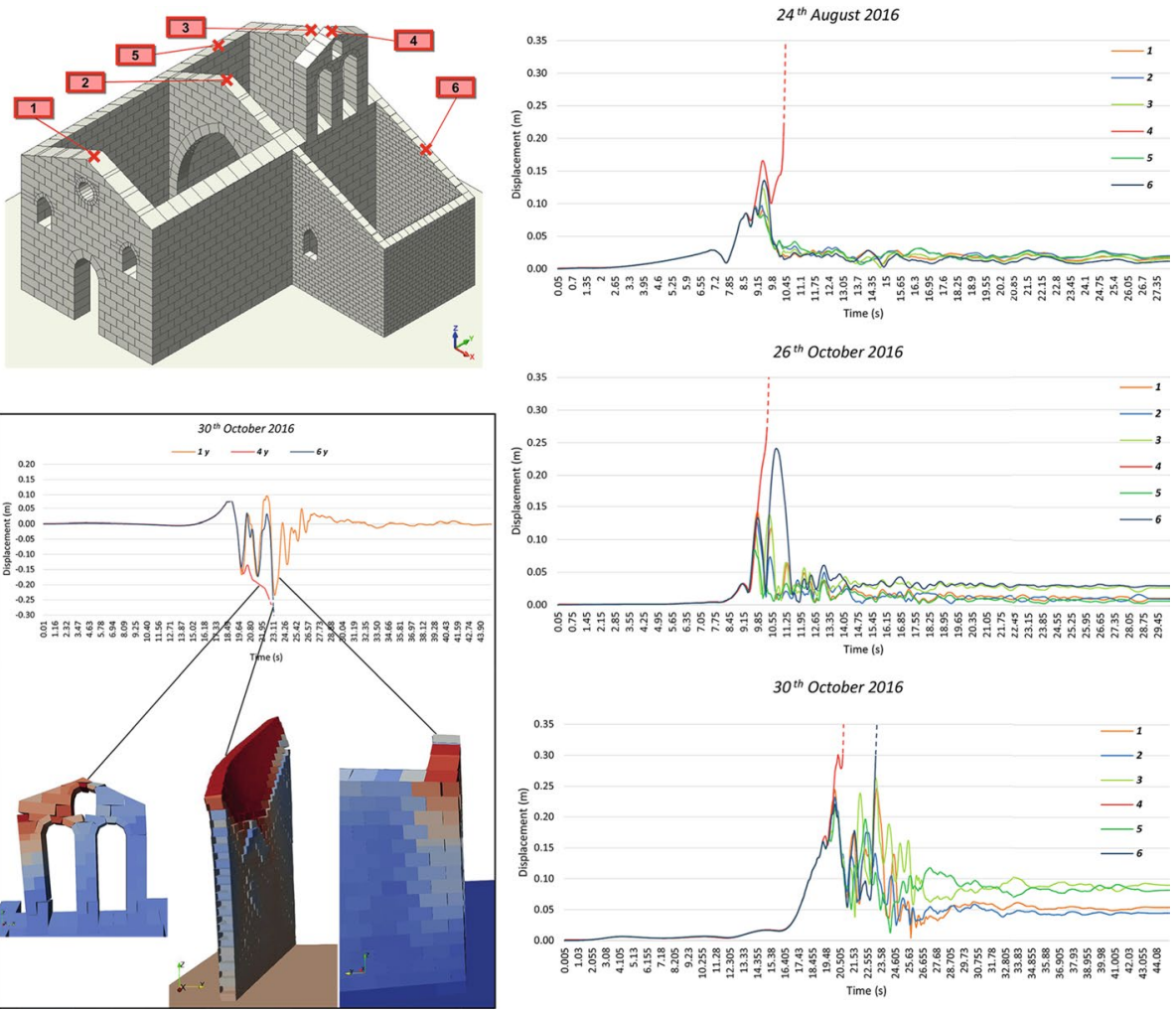

Fig. 27 Displacements time histories of different control nodes for the church of Sant'Antonio in Ussita (MC) for the three main shocks of Central Italy seismic sequence of 2016
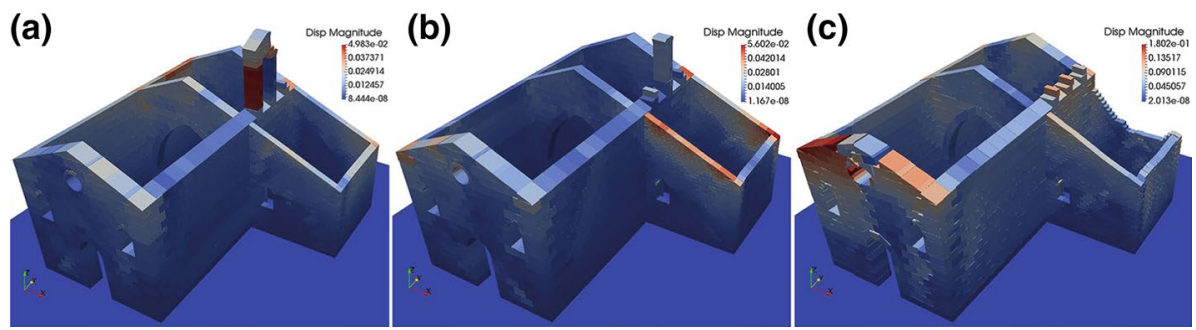

Fig. 28 Damages of the Church of Sant'Antonio in Ussita (MC) under the earthquakes of 24th August 2016 (a), 26th October 2016 (b), and 30th October 2016 (c)

except for the vault (\#3) and the bell-gable (\#4) that are strongly stressed until the collapse in correspondence of an increase of the vertical seismic action. These effects are visible in Figs. 32, 33 and 34.

For the earthquake of 26th October the vault (\#3) and the bell-gable (\#4) display more extensive damage (see Figs. 33 and 34) after the first increase of velocity as in the case of the 24th October earthquake. Contrary to what was noticed before, the walls 

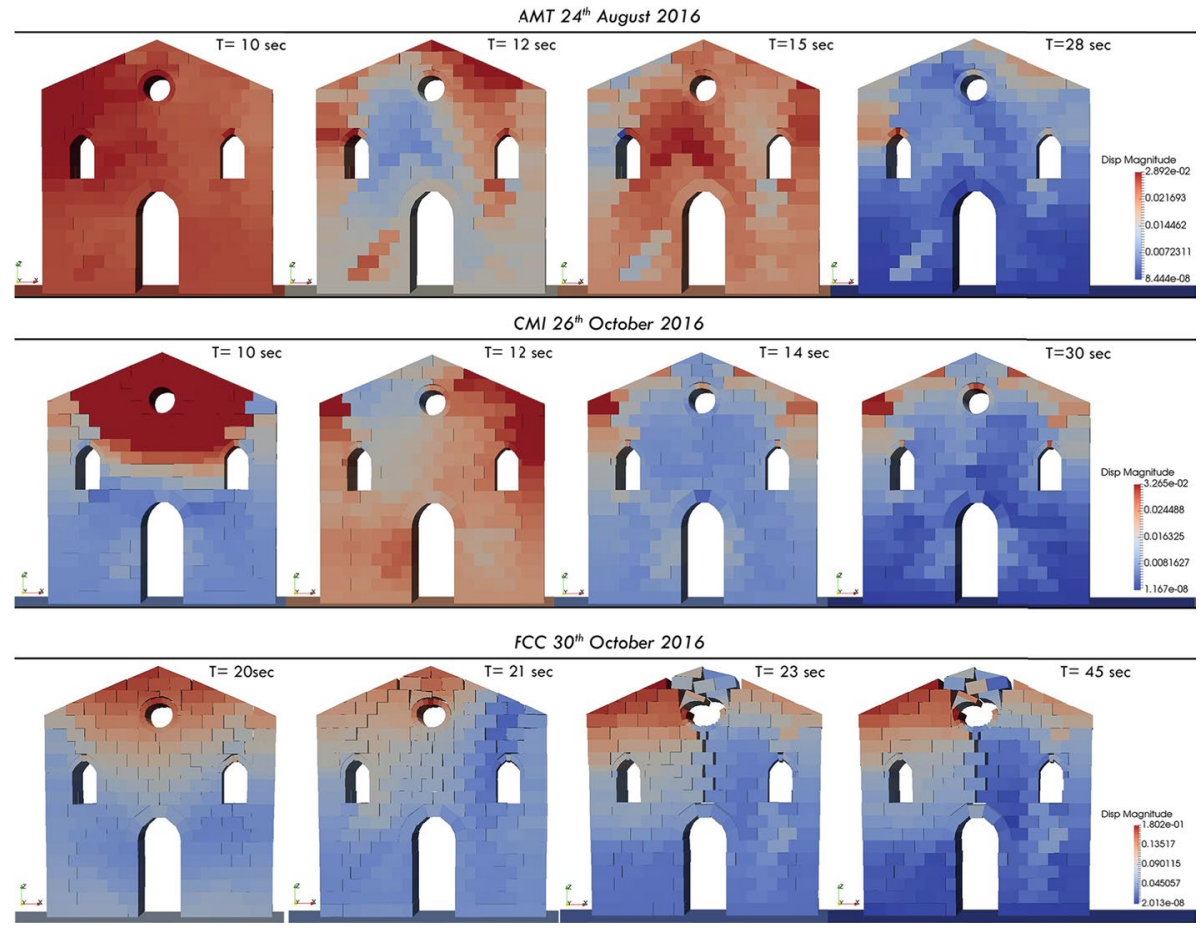

Fig. 29 Shear mechanisms of the façade of Sant'Antonio in Ussita (MC)
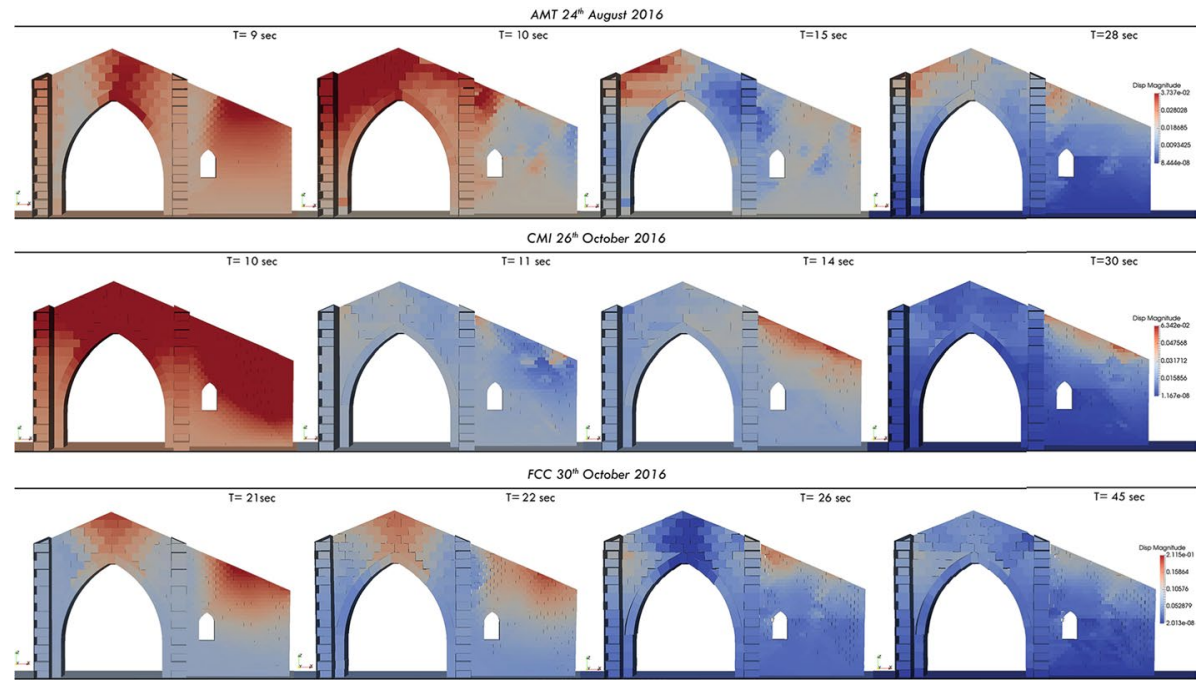

Fig. 30 Shear mechanisms of the triumphal arch of Sant'Antonio in Ussita (MC) 

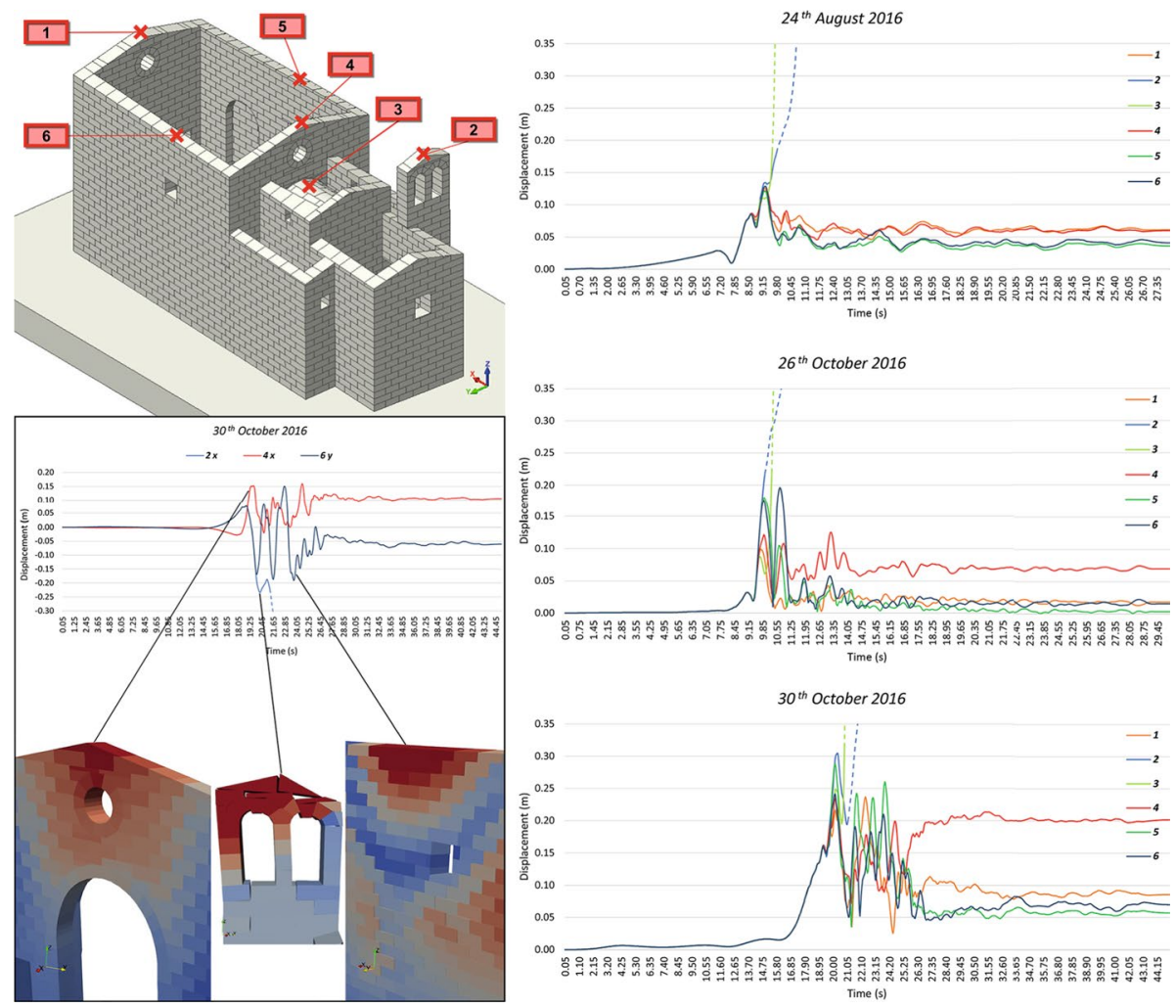

Fig. 31 Displacements time histories of different control nodes for the sanctuary of Madonna of Valcora in Fiuminata (MC) for the three main shocks of Central Italy seismic sequence of 2016

(a)

(b)

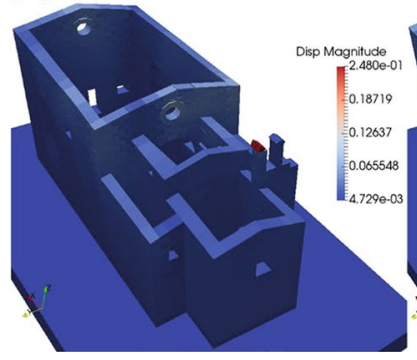

(c)
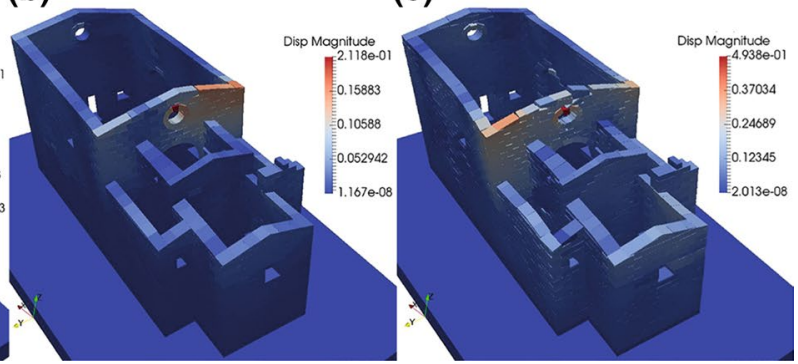

Fig. 32 Damages of the sanctuary of Madonna of Valcora in Fiuminata (MC)under the earthquakes of 24th August 2016 (a), 26th October 2016 (b), and 30th October 2016 (c)

of the nave (i.e., points \#6 and \#5) at the first peak of velocity exhibit the maximum displacements: this underlines a possible activation of in-plan mechanisms as shown in Fig. 34. At the end of the event, the triumphal arch (\#3) has the maximum residual displacement $\approx 8 \mathrm{~cm}$, highlighting an initial activation of an in-plane mechanism that can be observed in Fig. 33 for $t=30 \mathrm{~s}$. 

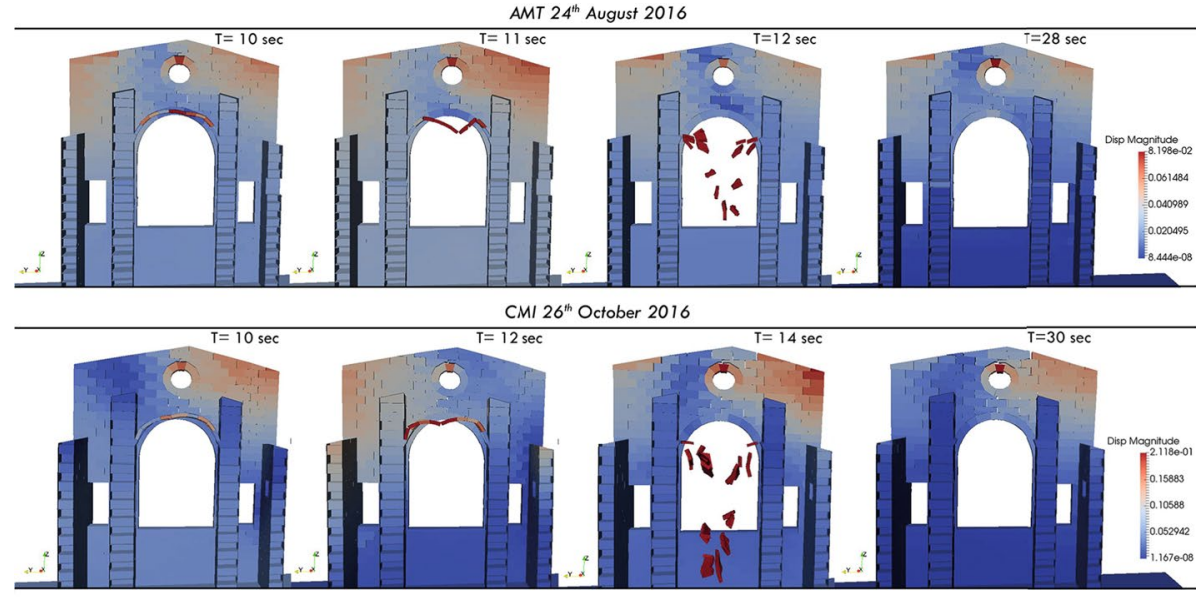

FCC $30^{\text {th }}$ October 2016

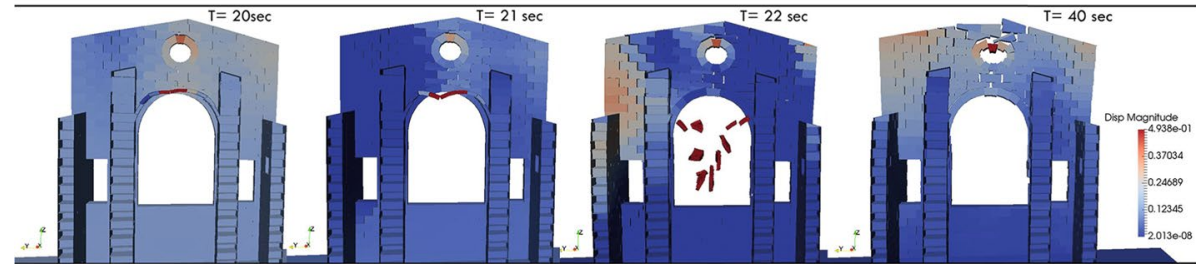

Fig. 33 Failure mechanism of the barrel vault of the apse of the sanctuary of Madonna of Valcora in Fiuminata (MC)
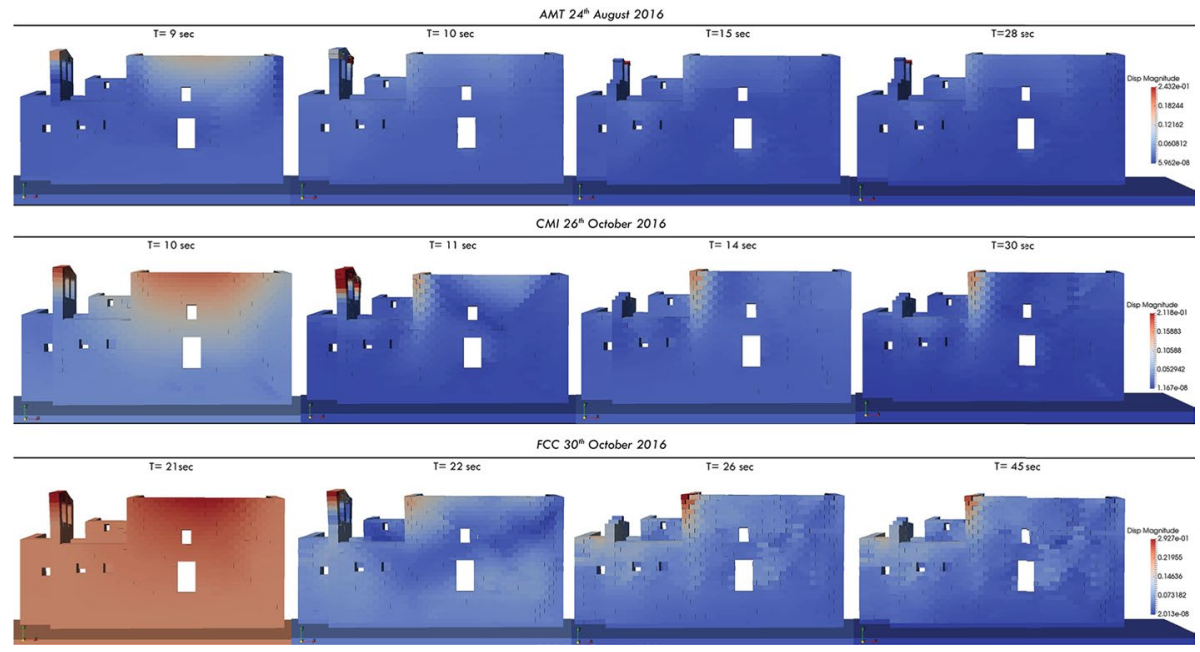

Fig. 34 Failure mechanism of the bell-tower and the triumphal arch of the sanctuary of Madonna of Valcora in Fiuminata (MC) 
Analyzing the most intense event, i.e., the 30th October earthquake, the increase of the displacements is evident in all points (see also the enlargement of Fig. 31). As in the previous event, the bell-gable (\#2) and the vault (\#3) collapse, whereas the triumphal arch (\#4) has a residual displacement of $20 \mathrm{~cm}$ which denoted an explicit activation of in-plane mechanism with a downward sliding of the key ashlar and the ashlars of the rose window (see Fig. 33).

At the end of the analyses, it can be said that the most vulnerable parts are the bell-gable $(\# 2)$, the barrel vault (\#3) and the triumphal arch (\#4) as also shown by the real earthquakes (Fig. 11).

\section{Conclusions}

The non-smooth contact dynamics method implemented in the LMGC90@ code has been applied to the study of the seismic response of ancient masonry churches inside the epicentral zone of the last Central Italy seismic sequence of 2016-2017.

The numerical results have pointed out different dynamical phenomena, which have confirmed the large potentialities of the NSCD method applying to masonry structures and have allowed to draw a detailed picture of the churches' vulnerabilities. In this study, the excitation of three real earthquakes is applied to the basement, and the induced damage is then investigated.

The numerical models used do not reproduce the exact stone blocks shapes but only the general joint patterns and the average dimensions of the units. Nevertheless, the models provided a fairly reliable representation of the observed displacement and near to collapse modes.

For all the analyzed churches, it was found that the bell-gable or the belfry is the most vulnerable element for every seismic event applied. Equally frequent damage mechanisms are the overturning of the façade out of its plane, and the in-plane mechanism of the triumphal arch which appears in all the various churches. Finally, frequently observed damages are the loss of equilibrium of little portions of the annexes as well as the collapse of vaults.

In all cases, the damaged portions highlighted by the numerical simulations coincide with the damage detected in the churches by the seismic sequence of Central Italy, confirming the susceptibility of these structures to typical vulnerabilities, and the capabilities of the used method.

Acknowledgements The authors wish to acknowledge the Soprintendenza Archeologia, Belle Arti e Paesaggio delle Marche and all the Municipalities for their valuable helps during the preparation of this work.

\section{References}

Acito M, Chesi C, Milani G, Torri S (2016) Collapse analysis of the Clock and Fortified towers of Finale Emilia, Italy, after the 2012 Emilia Romagna seismic sequence: lesson learned and reconstruction hypotheses. Constr Build Mater 115:193-213. https://doi.org/10.1016/j.conbuildmat.2016.03.220

Asteris PG, Sarhosis V, Mohebkhah A et al (2015) Numerical modeling of historic masonry structures. In: Asteris P, Plevris V (eds) Handbook of research on seismic assessment and rehabilitation of historic structures. IGI Global, Hershey, pp 213-256 
Betti M, Galano L, Vignoli A (2014) Comparative analysis on the seismic behaviour of unreinforced masonry buildings with flexible diaphragms. Eng Struct 61:195-208. https://doi.org/10.1016/j. engstruct.2013.12.038

Betti M, Borghini A, Boschi S et al (2018) Comparative seismic risk assessment of basilica-type churches. J Earthq Eng 22:62-95. https://doi.org/10.1080/13632469.2017.1309602

Brandonisio G, Lucibello G, Mele E, De Luca A (2013) Damage and performance evaluation of masonry churches in the 2009 L'Aquila earthquake. Eng Fail Anal 34:693-714. https://doi.org/10.1016/j. engfailanal.2013.01.021

Chetouane B, Dubois F, Vinches M, Bohatier C (2005) NSCD discrete element method for modelling masonry structures. Int J Numer Methods Eng 64:65-94. https://doi.org/10.1002/nme.1358

Clementi F, Quagliarini E, Maracchini G, Lenci S (2015) Post-world war II Italian school buildings: typical and specific seismic vulnerabilities. J Build Eng 4:152-166. https://doi.org/10.1016/j. jobe.2015.09.008

Clementi F, Gazzani V, Poiani M, Lenci S (2016) Assessment of seismic behaviour of heritage masonry buildings using numerical modelling. J Build Eng 8:29-47. https://doi.org/10.1016/j.jobe.2016.09.005

Clementi F, Pierdicca A, Formisano A et al (2017a) Numerical model upgrading of a historical masonry building damaged during the 2016 Italian earthquakes: the case study of the Podestà palace in Montelupone (Italy). J Civ Struct Heal Monit 7:703-717. https://doi.org/10.1007/s13349-017-0253-4

Clementi F, Quagliarini E, Monni F et al (2017b) Cultural heritage and earthquake: the case study of in Ascoli Piceno. Open Civ Eng J 11:1079-1105. https://doi.org/10.2174/1874149501711011079

Clementi F, Gazzani V, Poiani M et al (2018) Seismic assessment of a monumental building through nonlinear analyses of a 3D solid model. J Earthq Eng 22:35-61. https://doi.org/10.1080/13632 469.2017.1297268

Dubois F, Acary V, Jean M (2018) The contact dynamics method: a nonsmooth story. C R Mécanique 346:247-262. https://doi.org/10.1016/j.crme.2017.12.009

Fiorentino G, Forte A, Pagano E et al (2018) Damage patterns in the town of Amatrice after August 24th 2016 Central Italy earthquakes. Bull Earthq Eng 16:1399-1423. https://doi.org/10.1007/s1051 $8-017-0254-\mathrm{z}$

Formisano A (2016) Theoretical and numerical seismic analysis of masonry building aggregates: case studies in San Pio Delle Camere (L'Aquila, Italy). J Earthq Eng 21:1-19. https://doi. org/10.1080/13632469.2016.1172376

Formisano A, Marzo A (2017) Simplified and refined methods for seismic vulnerability assessment and retrofitting of an Italian cultural heritage masonry building. Comput Struct 180:13-26. https://doi. org/10.1016/j.compstruc.2016.07.005

Formisano A, Ciccone G, Mele A (2017) Large scale seismic vulnerability and risk evaluation of a masonry churches sample in the historical centre of Naples. In: Proceedings of the 13th International Conference of Computational Methods in Sciences and Engineering (ICCMSE 2017), Thessaloniki, Greece, pp 21-25. https://doi.org/10.1063/1.5012360

Formisano A, Vaiano G, Fabbrocino F, Milani G (2018) Seismic vulnerability of Italian masonry churches: the case of the Nativity of Blessed Virgin Mary in Stellata of Bondeno. J Build Eng 20:179-200. https://doi.org/10.1016/j.jobe.2018.07.017

Giordano E, Clementi F, Nespeca A, Lenci S (2019) Damage assessment by numerical modeling of Sant'Agostino's sanctuary in Offida during the Central Italy 2016-2017 seismic sequence. Front Built Environ 4:87. https://doi.org/10.3389/fbuil.2018.00087

Giresini L (2016) Energy-based method for identifying vulnerable macro-elements in historic masonry churches. Bull Earthq Eng 14:919-942. https://doi.org/10.1007/s10518-015-9854-7

Giresini L, Sassu M (2017) Horizontally restrained rocking blocks: evaluation of the role of boundary conditions with static and dynamic approaches. Bull Earthq Eng 15:385-410. https://doi. org/10.1007/s 10518-016-9967-7

Italian Department of Civil Protection (2017) 2016 Central Italy earthquake. http://www.protezionecivil e.gov.it/jcms/it/terremoto_centro_italia_2016.wp. Accessed Feb 2019

Kadas K, Yakut A, Kazaz I (2011) Spectral ground motion intensity based on capacity and period elongation. J Struct Eng 137:401-409. https://doi.org/10.1061/(ASCE)ST.1943-541X.0000084

Krstevska L, Tashkov L, Naumovski N, et al (2010) In-situ experimental testing of four historical buildings damaged during the 2009 L'Aquila earthquake. In: COST ACTION C26: urban habitat constructions under catastrophic events - proceedings of the final conference, pp 427-432

Lagomarsino S, Podestà S (2004) Damage and vulnerability assessment of churches after the 2002 Molise, Italy, Earthquake. Earthq Spectra 20:S271-S283. https://doi.org/10.1193/1.1767161

Lancioni G, Lenci S, Piattoni Q, Quagliarini E (2013) Dynamics and failure mechanisms of ancient masonry churches subjected to seismic actions by using the NSCD method: the case of the 
medieval church of S. Maria in Portuno. Eng Struct 56:1527-1546. https://doi.org/10.1016/j.engst ruct.2013.07.027

Lancioni G, Gentilucci D, Quagliarini E, Lenci S (2016) Seismic vulnerability of ancient stone arches by using a numerical model based on the non-smooth contact dynamics method. Eng Struct 119:110121. https://doi.org/10.1016/j.engstruct.2016.04.001

Lemos JV (2007) Discrete element modeling of masonry structures. Int J Archit Herit 1:190-213. https ://doi.org/10.1080/15583050601176868

Milani G (2013) Lesson learned after the Emilia-Romagna, Italy, 20-29 May 2012 earthquakes: a limit analysis insight on three masonry churches. Eng Fail Anal 34:761-778. https://doi.org/10.1016/j. engfailanal.2013.01.001

Milani G, Valente M (2015) Failure analysis of seven masonry churches severely damaged during the 2012 Emilia-Romagna (Italy) earthquake: non-linear dynamic analyses vs conventional static approaches. Eng Fail Anal 54:13-56. https://doi.org/10.1016/j.engfailanal.2015.03.016

Milani G, Shehu R, Valente M (2017) Role of inclination in the seismic vulnerability of bell towers: FE models and simplified approaches. Bull Earthq Eng 15:1707-1737. https://doi.org/10.1007/s1051 8-016-0043-0

Ministero dei Lavori Pubblici e dei Trasporti (2009) Circolare 2 febbraio 2009, n. 617 - Istruzioni per l'applicazione delle "Nuove Norme Tecniche per le Costruzioni" di cui al Decreto Ministeriale del $14 / 01 / 2008$ (in Italian)

Moreau JJ (1988) Unilateral contact and dry friction in finite freedom dynamics. In: Moreau JJ, Panagiotopoulos PD (eds) Nonsmooth mechanics and applications. Springer, Vienna, pp 1-82

Pantò B, Cannizzaro F, Caddemi S, Caliò I (2016) 3D macro-element modelling approach for seismic assessment of historical masonry churches. Adv Eng Softw 97:40-59. https://doi.org/10.1016/j.adven gsoft.2016.02.009

Pierdicca A, Clementi F, Isidori D et al (2016) Numerical model upgrading of a historical masonry palace monitored with a wireless sensor network. Int J Mason Res Innov 1:74-99. https://doi.org/10.1504/ IJMRI.2016.074748

Quagliarini E, Maracchini G, Clementi F (2017) Uses and limits of the equivalent frame model on existing unreinforced masonry buildings for assessing their seismic risk: a review. J Build Eng 10:166-182. https://doi.org/10.1016/j.jobe.2017.03.004

Roca P, Cervera M, Pelà L et al (2013) Continuum FE models for the analysis of Mallorca Cathedral. Eng Struct 46:653-670. https://doi.org/10.1016/j.engstruct.2012.08.005

Sarhosis V, Milani G, Formisano A, Fabbrocino F (2018) Evaluation of different approaches for the estimation of the seismic vulnerability of masonry towers. Bull Earthq Eng 16:1511-1545. https://doi. org/10.1007/s10518-017-0258-8

Terracciano G, Di Lorenzo G, Formisano A, Landolfo R (2015) Cold-formed thin-walled steel structures as vertical addition and energetic retrofitting systems of existing masonry buildings. Eur J Environ Civ Eng 19:850-866. https://doi.org/10.1080/19648189.2014.974832

Valente M, Milani G (2016) Seismic assessment of historical masonry towers by means of simplified approaches and standard FEM. Constr Build Mater 108:74-104. https://doi.org/10.1016/j.conbuildma t.2016.01.025

Valente M, Milani G (2018) Seismic response and damage patterns of masonry churches: seven case studies in Ferrara, Italy. Eng Struct 177:809-835. https://doi.org/10.1016/j.engstruct.2018.08.071

Vasconcelos G, Lourenço PB (2009) Experimental characterization of stone masonry in shear and compression. Constr Build Mater 23:3337-3345. https://doi.org/10.1016/j.conbuildmat.2009.06.045

Zuccaro G, Cacace F (2015) Seismic vulnerability assessment based on typological characteristics. The first level procedure "SAVE". Soil Dyn Earthq Eng 69:262-269. https://doi.org/10.1016/j.soild yn.2014.11.003 